\title{
Caracterização do perfil e dos principais direcionadores de transições em escritórios de projetos: Estudo de caso longitudinal em uma empresa de alta tecnologia
}

\author{
Characterization of profile and main drivers for transitions in project \\ management offices: A longitudinal case study in a high-tech company
}

\author{
Sanderson César Macêdo Barbalho' \\ José Carlos Toledo²
}

\begin{abstract}
Resumo: Este trabalho objetiva, por meio da abordagem de estudo de caso longitudinal, apresentar e analisar a mudança evolutiva da atuação e do desempenho do Escritório de Projetos (PMO) de uma empresa de base tecnológica. O estudo tem caráter exploratório enfocando o entendimento dos elementos que motivaram as transições ocorridas no PMO ao longo de 13 anos de atuação. Para tal, foram levantadas informações relativas às funções exercidas pelo PMO ao longo desse período, assim como as relações deste com gerentes e equipes de projetos, gerentes funcionais e alta administração. Dados representativos do desempenho dos projetos e do PMO são apresentados. Verificou-se que as tensões vivenciadas são os principais motivadores das mudanças, sendo estas determinadas pelas funções e resultados apresentados pelo escritório. O estudo permitiu construir um quadro explicativo das transições que atingem o PMO, o qual pode ser utilizado para a realização de estudos mais abrangentes e de caráter mais descritivo.

Palavras-chave: Gestão de Projetos. Estrutura organizacional. Escritórios de gerenciamento de projetos. Desenvolvimento de novos produtos.
\end{abstract}

\begin{abstract}
Through the longitudinal case study approach, this paper aims to present and analyze the evolutionary change of the procedure and performance of a technology-based company Project Management Office (PMO). The study has exploratory character and focuses on understanding the factors that motivated the transitions occurring in the PMO over 13 years of experience. To this end, information was raised on the functions performed by the $P M O$ during this period, as well as its relations with managers and project teams, functional managers and senior management. Representative performance data about projects and PMO are presented. It was found that experienced tensions are the main drivers of change, which are determined by the functions and results shown by the office. The study allowed the construction of a framework to explain the transitions that reach PMO, which can be used to conduct more comprehensive studies in more descriptive character.
\end{abstract}

Keywords: Project Management. Organizational structure. Project management office. New product development.

\section{Introdução}

O Escritório de Projetos, do inglês "Project Management Office" (PMO), é a estrutura organizacional estabelecida para facilitar as atividades da gestão de projetos (GP) e trazer melhorias ao processo de gestão da organização por meio da gestão do portfólio e do alinhamento de projetos com a estratégia corporativa (CRAWFORD, 2002). A atuação dos Escritórios, em várias empresas, evoluiu do foco em projetos relativamente simples e isolados para ambientes multiprojetos e de projetos complexos, passando do desempenho de funções de controle e suporte para a gestão global do conjunto de projetos, alinhada às estratégias do negócio. Considera-se hoje que o aspecto organizacional da GP é uma das principais questões abertas às pesquisas na área, especialmente quanto ao papel dos PMOs habilitando e executando processos de mudança organizacional (BREDILLET, 2010).

Trabalhos como os de Hobbs e Aubry (2007), Aubry, Hobbs e Thuillier (2007), Hobbs, Aubry e Thuillier (2008), Pellegrinelli e Garagna (2009), Aubry et al. (2010b) apontam para a multiplicidade de funções exercidas pelos PMOs e para a importância destes para os processos de mudança organizacional. Tais

${ }^{1}$ Departamento de Engenharia de Produção, Universidade de Brasília - UnB, CEP 70910-900, Brasília, DF, Brasil,

e-mail: sandersoncesar@unb.br

2 Departamento de Engenharia de Produção, Universidade Federal de São Carlos - UFSCar, CEP 13565-905, São Carlos, SP, Brasil, e-mail: toledo@dep.ufscar.br

Recebido em 7/10/2012 — Aceito em 12/5/2014

Suporte financeiro: Nenhum. 
estudos demonstram que os PMOs têm enfoque em atividades de monitoramento e controle dos projetos, reporte para a gerência sênior e desenvolvimento de metodologias para gestão de projetos. Dados empíricos mostram ainda que os PMOs não são estruturas organizacionais estáticas, mas, ao contrário, sofrem transições constantes de maneira a refletir a estratégia do negócio.

Tais transições, embora fundamentais para a efetividade do PMO na empresa, não foram ainda bem compreendidas. Sabe-se que elas ocorrem ora aumentando o caráter suportivo, ora o de controle dos PMOs (AUBRY et al., 2010a), que elas têm origem tanto no contexto interno quanto externo à empresa (AUBRY et al., 2010a), porém não se avançou no entendimento dos mecanismos pelos quais elas atuam.

Este artigo apresenta um estudo de caso longitudinal acerca de um Escritório de Projetos de uma empresa de base tecnológica localizada no interior do Estado de São Paulo. O objetivo é demonstrar a lógica que fundamentou as transições na estrutura e funcionamento do PMO, assim como o desempenho dos projetos em cada um dos estágios do escritório. O período analisado, outubro de 1999 a junho de 2012, representa todo o período no qual a empresa manteve um escritório de projetos. Almeja-se contribuir para as teorias que buscam entender a evolução dos PMOs dentro de empresas que dependam total ou parcialmente de projetos, como também para o delineamento das funções dos PMOs que servem às áreas de inovação e de desenvolvimento de produtos nas organizações.

A seção 2 apresenta o referencial teórico da pesquisa detalhando a literatura corrente relacionada aos PMOs. A seção 3 consolida a literatura estabelecendo um modelo analítico para o levantamento e análise dos dados de campo com vistas a discutir o problema das transições nos PMOs. A seção 4 discute a abordagem metodológica utilizada. Apresenta-se o estudo de caso na seção 5 com a descrição detalhada de cada estágio do PMO analisado. Cada estágio é comparado sob o ponto de vista dos tipos de funções exercidas pelo escritório e depois dos resultados obtidos pelos projetos. A seção 6 objetiva apresentar uma visão integrada das variáveis analisadas em função dos dados levantados em campo. A seção 7 apresenta as considerações finais do trabalho.

\section{Escritórios de projetos}

\subsection{Tipologias e funções}

Para Crawford (2002), há diferenças significativas entre os PMOs em função do nível hierárquico ao qual atende. A autora classifica os escritórios segundo níveis, conforme a Figura 1.

O nível 1 do escritório de projetos é característico de grandes e complexos projetos únicos, sendo totalmente voltados ao projeto que o criou. Nesse nível, o PMO exerce funções de suporte ao gerente de projetos muitas vezes estando subordinado diretamente a ele. Tais funções vão da elaboração e manutenção dos cronogramas de projeto, atividades de monitoramento e controle das áreas de conhecimento da GP até atividades de secretaria, agendamento de eventos e arquivo de documentos. O PMO nível 2 ocorre quando o foco do escritório não é um projeto em si, mas todos os projetos de uma unidade de negócios. Nesse caso, o PMO tem a função de realizar a gestão de recursos direcionados aos projetos da unidade.

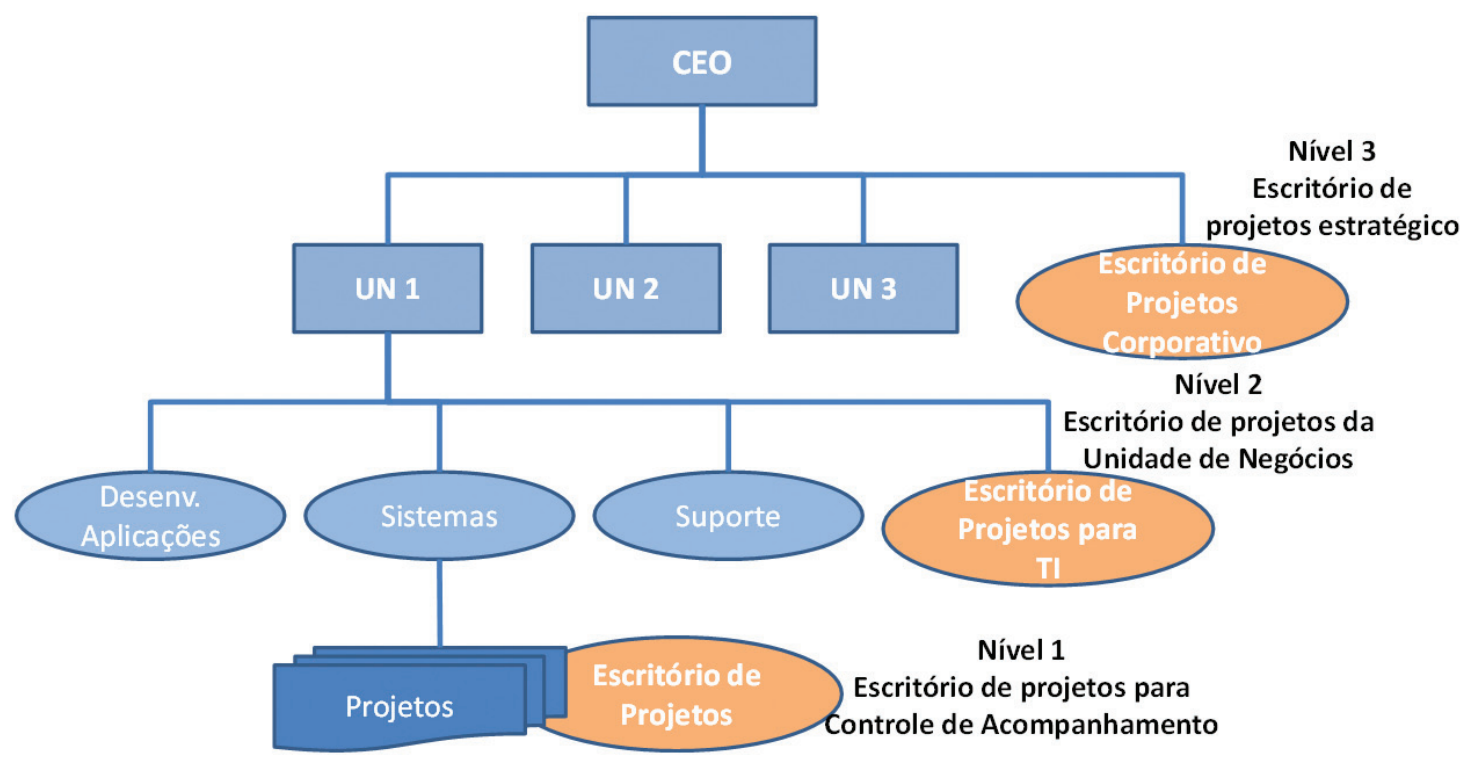

Figura 1. Níveis de atuação do Escritório de Projetos (CRAWFORD, 2002). 
Para tal, é importante desenvolver metodologias padronizadas que possam ser customizadas para cada projeto em específico, assim como criar métricas para priorização dos projetos que competem por recursos. Seu vínculo com a gerência ou diretoria da área é fundamental.

O nível 3 se trata de um PMO com vínculo direto com o principal executivo da empresa, objetivando dar suporte para a GP de todas as unidades de negócio da organização. Esta estrutura, portanto, permite viabilizar projetos e programas alinhados às estratégias da organização e não somente de uma unidade de negócio. Pode também, ser o caso de ter atuação em um ou mais projetos específicos que pelo seu grau de criticidade para a estratégia da empresa estão sob o comando direto do executivo principal.

A Figura 1 passa a impressão de que os escritórios de projeto ascendem na empresa de uma maneira linear. Ou seja, a empresa constituiria inicialmente um escritório de projetos nível 1 para dar suporte à gestão de um projeto complexo de uma determinada unidade de negócios. Em função do tempo e dos resultados, o escritório passa a ser de nível 2, talvez porque outros projetos tão importantes quanto o primeiro estejam em andamento e precisem utilizar metodologias compartilhadas ou disputam recursos que precisam ser controlados por uma unidade neutra em relação a eles. À medida que a metodologia e os resultados do escritório se consolidam ele seria alçado a um escritório nível 3 em função também de demandas do executivo principal para a consolidação de uma gestão de portfólio mais apropriada e alinhada às metodologias de gestão de projetos e programas desenvolvidas pelo escritório. É importante ter cuidado com essa visão, pois, embora seja algo possível e há relatos que corroboram com esse perfil de mudança (MARTINS et al., 2005; BARBALHO et al., 2009), pode ser que escritórios diferentes, compostos por pessoal diferente, com um gestor diferente e com histórico de constituição independente um do outro ocupem os níveis apresentados.

De fato, os estudos de Aubry et al. (2010a, b) sugerem que há diversos tipos de transições a que os escritórios de projetos estão submetidos e que ocorrem em um mesmo nível de Crawford (2002), portanto, não seguindo a lógica defendida por esta última. Essas transições se refletem mais em mudanças nas suas funções dentro da empresa que na sua ascensão ou queda na hierarquia. Funções dos PMOs são outro importante objeto de estudo na área. Hobbs e Aubry (2007) descrevem um estudo com 500 PMOs canadenses, americanos e australianos com o objetivo de levantar seu modus operandi para caracterizá-los mais assertivamente. Analisou-se a presença e o grau de importância de 27 diferentes funções e papéis atribuídos aos PMOs. Essas funções e papéis foram submetidos à análise fatorial gerando os seguintes grupos: (1) atividades de monitoramento e controle do desempenho dos projetos; (2) desenvolvimento de competências e metodologias de GP; (3) gerenciamento multiprojeto; (4) gestão estratégica; (5) aprendizagem organizacional; (6) execução de tarefas especializadas para os gerentes de projeto; (7) gerenciamento de interfaces com clientes; e (8) recrutamento, seleção e determinação dos salários dos gerentes de projeto.

Para Hobbs e Aubry (2007), na média, as atividades de monitoramento e controle do desempenho dos projetos são as mais importantes dentro dos PMOs. Os autores sugerem que há uma correlação direta entre os PMOs e a maturidade em GP. Tal relação é descrita como sendo circular: PMOs aumentam a maturidade em GP da empresa; a maturidade reforça o trabalho do PMO; e assim sucessivamente. A perspectiva de aumento na maturidade é reforçada pelas evidências das pesquisas de Crawford (2006), Rodrigues, Rabechini Júnior e Csillag (2006) e Silveira, Sbragia e Kruglianskas (2013), este último enfatizando que as funções desempenhadas pelos PMOs podem gerar resultados, mas a maturidade da organização em GP pode limitar o impacto desses resultados no desempenho dos projetos.

\subsection{Tensões e transições em PMO}

Rodrigues, Rabechini Júnior e Csillag (2006) realizaram estudo descritivo acerca de escritórios de projeto, tendo observado que os escritórios pesquisados apresentavam baixo grau de aderência aos modelos teóricos estabelecidos até então. Essa não aderência é também identificada em Aubry, Hobbs e Thuiller (2007), que consideram que a pesquisa em gestão de projetos tem adotado uma perspectiva que dificulta o entendimento de como os PMOs devem ser concebidos e gerenciados em empresas que não trabalham exclusivamente com projetos para atender a seus objetivos de negócio.

Tal perspectiva motivou o estudo descrito em Hobbs, Aubry e Thuillier (2008), no qual 11 PMOs foram analisados por cerca de 10 anos. Os autores verificaram que as empresas reconfiguram seus escritórios a cada 3 ou 4 anos, motivadas, entre outros elementos, por tensões internas à empresa. As tensões envolvidas seriam: (1) econômica - relacionada ao desempenho dos projetos e ao custo do PMO; (2) política - relativa especialmente à gestão dos projetos e à comunicação da situação dos prazos e custos para a empresa; (3) relacionamento com o cliente - seja o cliente final do projeto ou seus clientes internos; (4) padronização e flexibilização dos procedimentos do PMO - uma orientação para o negócio resulta em demandas práticas da execução dos projetos que, muitas vezes, exigem flexibilidade não existente no processo gerenciado pelo PMO; e 
(5) o controle sobre o projeto - reflete a tensão entre a equipe do projeto e a área funcional, especialmente no que tange aos recursos necessários à execução dos projetos. Segundo os autores, a variedade de PMOs encontrados é consequência das respostas que cada empresa dá às tensões acima elencadas e sobre elas incidem ainda os eventos externos ou internos de um dado contexto empresarial.

Pellegrinelli e Garagna (2009) demonstram que o sucesso do PMO traz um risco iminente de que ele seja considerado desnecessário à medida que consolide as metodologias e ferramentas de GP na empresa. Os líderes de PMO devem buscar continuamente gerar novos valores por meio da redefinição de seus propósitos e objetivos, o que estaria na base das transições experimentadas por alguns escritórios. Barbalho et al. (2009) descrevem uma situação de transição de um PMO, no qual os obstáculos para a implantação de práticas de nível 2 tinham base em tensões entre o PMO e os gerentes e equipes de projeto em função do aspecto de controle sobre o projeto e da comunicação de seus resultados. Foi necessário incorporar atividades de suporte operacional de maneira a diminuir a tensão criada com esses grupos. Aubry et al. (2010a) apresentaram estudo de casos múltiplos sobre os direcionadores de mudança nas atividades dos PMOs. Segundo os autores, transições são comuns e necessárias aos escritórios, como garantia da relevância destes para o desenvolvimento da organização.

Aubry et al. (2010b) apresentam resultados de um survey global com 184 PMOs cujo objetivo foi levantar os principais aspectos relacionados às transições nos PMOs dentro das organizações de maneira geral. Os autores encontraram o seguinte:

- Os principais elementos que direcionam as mudanças nos PMOs são alterações em fatores externos à empresa ou na composição da alta gerência. Aspectos internos como insatisfação com resultados dos projetos, competição com outras partes da organização pelo uso de recursos ou mudança na gerência do PMO não foram encontrados como fatores relevantes para explicar as transições;

- Quando realizadas as mudanças, quatro são os principais objetivos da organização: (1) melhoria na utilização de métodos e ferramental geral de gestão de portfólios; (2) aumento da maturidade em gestão de projetos e no desempenho deles; (3) estreitamento das relações entre os gerentes, seus clientes e stakeholders - especialmente os gerentes funcionais -, e estabelecimento de processos que permitam às áreas da empresa receber bônus e benefícios vinculados às entregas dos projetos; e (4) melhoria no ambiente de trabalho e equilíbrio trabalho-família do pessoal de projetos;

- Do ponto de vista operacional, as mudanças se agrupam em três diferentes tipos de ação: (1) "caráter de apoio do PMO", com funções como gestão multiprojetos, desenvolvimento de competências em GP e realização de auditorias com registro e utilização de lições aprendidas; (2) "caráter de controle", incluindo o aumento do nível hierárquico ao qual o PMO responde, o aumento do percentual de projetos gerenciados pelo PMO e o aumento do percentual de gerentes de projeto respondendo ao escritório; (3) a autonomia do PMO na empresa, provendo maior autoridade para a tomada de decisões sobre os projetos, programas e portfólios;

- Quanto aos resultados, os principais impactos das transições experimentadas pelos PMOs nas empresas seriam: (1) melhoria na seleção de projetos; (2) aumento da colaboração dos gerentes e equipes funcionais com relação às atividades dos projetos; (3) maior comprometimento da organização com o gerenciamento de projetos; e (4) maior disponibilidade de informações relevantes para a tomada de decisões relacionadas a projetos, programas e portfólios.

Embora tenha conseguido levantar diversos elementos relacionados às transições nos PMOs, o estudo é limitado quando tenta correlacioná-los ao explicar a lógica que embasa as mudanças que ocorrem nos escritórios, sendo, porém, uma referência básica do estudo aqui apresentado. Estudo adicional do grupo, descrito em Aubry e Hobbs (2011) analisa diferentes perspectivas de desempenho organizacional que impactam a estrutura de trabalho dos PMOs, tendo verificado que, dependendo do enfoque dado ao desempenho organizacional pela própria corporação - curto, médio, longo prazo, indicadores financeiros, de clima organizacional etc. -, o papel do PMO é alterado de maneira a alinhar seus resultados às demandas da empresa.

Alves et al. (2013) realizaram análise em 51 PMOs de diferentes setores da economia brasileira estudando a implantação dos escritórios de projetos. Impactos da implantação seriam sentidos ao longo dos anos pelos escritórios. Os resultados colhidos pelos autores corroboram a literatura internacional, demonstrando que bons direcionadores de desempenho na implantação de escritórios são a obtenção de patrocínio da alta administração e a alocação no PMO de profissionais sêniores que reconheçam tal esforço como mudança cultural na empresa. 


\subsection{Fatores críticos de sucesso para a atuação dos PMOs}

Análise da literatura relacionada ao desempenho dos projetos e dos escritórios de projetos em empresas de diversos segmentos demonstrou que a presença de alguns fatores, seja na organização como um todo, seja na metodologia de atuação do PMO, influencia no sucesso do escritório de projetos tendo, portanto, impacto sobre sua evolução dentro da empresa. De acordo com Martins et al. (2005), Rodrigues, Rabechini Júnior e Csillag (2006), Maximiano e Anselmo (2006), Carvalho et al. (2005), Mullaly (2006), Barbalho et al. (2009), Pellegrinelli e Garagna (2009) e Alves et al. (2013), tais fatores são: (1) os resultados alcançados no desempenho dos projetos; (2) o suporte da alta gerência na demarcação do espaço político do PMO na empresa; (3) o suporte dos gerentes funcionais; (4) a existência de um profissional dedicado à implantação da GP (um champion) na empresa; (5) o efetivo suporte às equipes de projeto na empresa de maneira a mitigar tensões entre estas e o PMO; (6) os resultados efetivos de incorporação de melhores práticas em GP na empresa; e (7) a busca contínua de geração de novos valores por meio da redefinição de seus propósitos e objetivos na organização.

Ou seja, resultados, práticas de GP consolidadas, suporte das principais partes interessadas e busca por inovações organizacionais são os principais fatores a serem buscados para o êxito dos PMOs. Uma das hipóteses do trabalho é a de que o perfil de evolução sugerido por Crawford (2002) se beneficia do alinhamento do PMO a esses fatores de sucesso.

\section{Quadro teórico do trabalho para efeitos analíticos}

Sumarizando a discussão anterior, a pesquisa aqui apresentada busca entender os conceitos envolvidos nas transições pelas quais passam os PMOs com base nos aspectos levantados pela literatura científica, conforme o quadro esquemático apresentado na Figura 2.

Assim, depreende-se do referencial teórico apresentado anteriormente que as transições, as quais um PMO pode experimentar, têm relação

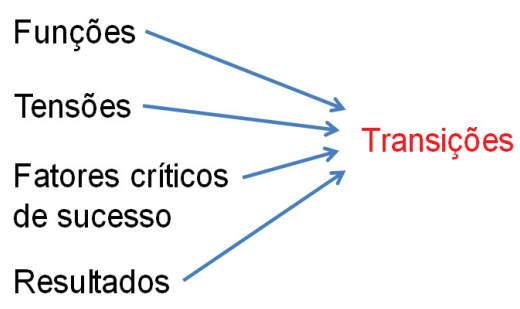

Figura 2. Quadro teórico do trabalho. com as funções por ele desempenhadas, baseadas em Hobbs e Aubry (2007); devem sofrer influência das tensões às quais está sujeito (HOBBS; AUBRY; THUILLIER, 2008); e ocorrem em um contexto no qual os fatores críticos de sucesso dos PMOs identificados na bibliografia são ou não atendidos. Dentre os fatores críticos de sucesso, optou-se por separar o aspecto dos resultados dos projetos e do próprio PMO dos demais listados na seção 2.3 , em função de haver nesse elemento um aspecto mais objetivo, passível, portanto, de ser medido; além do fato de ter relação com o objetivo final das práticas de gerenciamento de projetos, qual seja o sucesso do projeto e/ou produto resultante para o resultado operacional da empresa.

A análise da bibliografia mostrou que as relações entre os elementos apresentados na Figura 2 não são bem estabelecidas na literatura científica. Por exemplo, as funções que o PMO exerce criam tensões que impactam nos fatores críticos de sucesso dos PMOs? Como essas relações geram transições? Como caracterizar essas transições? Qual o papel dos resultados efetivos dos projetos/produtos nas transições pelas quais passam os PMOs?

Enfim, o trabalho é construído sob a hipótese geral de que as funções exercidas pelos PMOs; as tensões sob as quais atua na empresa; os fatores críticos de sucesso elencados - relações com gerentes de projeto e com gerentes funcionais, perfil do líder do PMO, relações com as equipes de projeto e perfil do suporte da alta gerência para a atuação do PMO; e os resultados que os PMOs geram ou contribuem para que sejam gerados pelos projetos são elementos motivadores das transições pelas quais passam os escritórios de projeto. Entender a lógica pela qual esses motivadores atuam por meio de uma pesquisa exploratória é o objetivo deste trabalho e sua contribuição para a literatura nesse campo.

\section{Abordagem metodológica}

O presente trabalho apresenta as seguintes características, segundo diversos autores (GODOY, 1995; YIN, 2008; VOSS; TSIKRIKTSIS; FROHLICH, 2002): análise indutiva; dados de natureza qualitativa; caráter descritivo das variáveis e objetivos gerais da pesquisa de cunho exploratório. A partir dessas características - descritas a seguir - a abordagem de estudo de caso é adotada.

A análise é indutiva, pois a linha de análise é do específico para o geral, embora com limitações na generalização dos resultados por se tratar de apenas uma unidade de análise. A maioria dos dados é de natureza qualitativa, devido ao tipo de variáveis, cujos resultados são representados de forma descritiva, com algumas relações de causalidade, embora haja dados quantitativos coletados para o teste da relação entre os resultados dos projetos e as transições experimentadas 
pelo PMO. O trabalho é de natureza exploratória, pois a literatura é relativamente limitada no foco escolhido, seja pelo tema no nível teórico (evolução e dinâmica de PMO), seja pela investigação empírica em uma dada empresa. Tanto o contexto quanto o fenômeno são importantes no presente estudo, justificando então a adoção da abordagem de estudo de caso, que se mostra a mais adequada a partir das características apresentadas.

Segundo Yin (2008), o estudo de caso longitudinal é aplicado quando se deseja estudar um caso único em dois ou mais diferentes pontos ao longo do tempo, focando na evolução de um aspecto em particular, no caso aqui relatado, a evolução de escritórios de projetos. A coleta das informações foi feita considerando 13 anos, entre 1999 e 2012. De acordo com Voss, Tsikriktsis e Frohlich (2002), quanto maior o período que o fenômeno é estudado, maior a oportunidade de observar a sequência relacional de eventos ocorridos. Outras vantagens associadas ao estudo de caso longitudinal são: (1) acesso a uma grande fonte de dados ao longo do tempo, fato esse que não ocorre com outros métodos (KARLSSON; AHLSTRÖM, 1995); (2) permite a repetição das observações/coleta de dados, fornecendo maior confiabilidade às informações coletadas e às conclusões extraídas (HEDEKER; GIBBONS, 2006); e (3) permite estudar/medir a mudança e possíveis explicações dessa mudança, fato esse que é difícil de ser feito por outros métodos (MENARD, 2002).

Nesse tipo de estudo, é importante utilizar múltiplas fontes para coleta de dados para obtenção de resultados mais robustos (EISENHARDT, 1989). Seguindo essa diretriz e baseando-se em Yin (2008), o presente estudo utilizou-se das seguintes técnicas de coleta de dados: (1) observação participante - com essa técnica, o pesquisador via a realidade do ponto de vista de dentro da empresa, coletando alguns tipos de dados de muita importância e que seriam muito difíceis de serem conseguidos sem alguém imerso no ambiente pesquisado; (2) análise de documentos e registros do sistema de gestão da empresa; e (3) entrevistas semiestruturadas com os engenheiros, gerentes e diretores responsáveis pelos projetos.

As seguintes etapas correspondem à condução do estudo de caso aqui relatado:

- Observação participante. Realizada ao longo de 10 anos por um dos autores do texto. Utilizaram-se cadernos individuais para registrar atividades de projeto e de gestão de projetos. Os registros eram categorizados e datados de acordo com o sistema de gestão ISO 9001 da empresa. Esses registros eram tanto relacionados a planejamento, quanto relativos à execução, monitoramento e controle dos projetos, participação em revisões formais com clientes e elaboração de propostas e cotações de projetos que foram posteriormente contratados e executados sob coordenação do escritório de projetos pesquisado. A metodologia sugerida por Serva e Jaime Júnior (1995), que é baseada no uso de "rubricas de pesquisa", foi utilizada quando da sistematização dos registros de campo em busca de evidências sobre os elementos que caracterizam os estágios dos escritórios de projeto.

- Análise documental dos procedimentos operacionais, pela leitura de relatórios executivos e registros do sistema de gestão de projetos da empresa contendo a situação dos projetos em andamento ao longo do período analisado. Foram levantadas atas de reuniões e documentos complementares que possuíam informações sobre a condução dos projetos; relatórios de clientes com itens de ação a serem cumpridos pela empresa, especialmente relacionados às práticas de gestão de projetos; termos de contrato e termos de abertura de licitações que a empresa celebrou ou participou, dando enfoque às práticas de gestão de projetos demandadas em tais documentos. A análise documental foi realizada utilizando a vertente categorial descrita em Bardin (1979). As categorias analisadas nos documentos pesquisados são aquelas identificadas no quadro teórico do trabalho (Figura 2), assim como suas subdivisões, conforme discutido na seção 2 do artigo.

- Proposição de uma estrutura que representasse os estágios de evolução do PMO. Essa atividade foi realizada pelos pesquisadores em meados de 2012 de maneira a sistematizar os dados de observação participante e de análise documental, visando construir um entendimento sobre os estágios de evolução do PMO. Uma versão inicial foi utilizada para subsidiar a discussão com os gerentes de projeto, engenheiros e com a diretoria da área, de maneira a validar os estágios identificados, tanto temporalmente quanto relativo à caracterização. A discussão gerada subsidiou alterações na proposta inicial e compilação dos estágios apresentados neste texto.

- Levantamento de material quantitativo acerca do desempenho dos projetos ao longo dos estágios consolidados na etapa anterior. Os dados foram consolidados ao longo dos anos pelo escritório de projetos da empresa e disponibilizados aos pesquisadores considerando um conjunto de dados que representasse o desempenho dos 
projetos e, paralelamente, não expusessem a empresa a constrangimentos ou ferissem contratos de sigilo. Por esse motivo, apenas indicadores relativos a prazos de projetos foram utilizados. De posse desses dados, os pesquisadores consolidaram as informações quantitativas apresentadas: número de projetos por estágio, tempo decorrido em meses por estágio e lead-time médio em dias dos projetos iniciados em cada estágio.

- Realização de entrevistas com o pessoal envolvido no escritório de projetos por meio de um roteiro, no qual aspectos relativos às tensões, funções, resultados e demais fatores críticos experimentados pelo PMO foram levantados. $\mathrm{O}$ roteiro foi aplicado a cinco engenheiros que coordenavam as tarefas de GP na empresa quando realizada essa etapa da pesquisa (meados de 2012). Esta coleta de dados objetivou, mais uma vez, testar e validar os estágios propostos, bem como caracterizá-los melhor em termos de funções exercidas pelo PMO em cada um, assim como levantar elementos que explicassem a transição entre eles. Cada entrevista foi realizada por um dos autores após a leitura por parte dos entrevistados do documento mencionado no item (3) anterior. O roteiro consistia nos tópicos apresentados no quadro teórico (Figura 2) mediante questões abertas de maneira a não influenciar a linha de raciocínio dos entrevistados.

- Realização de validação final com a diretoria de projetos e seus principais gerentes. Essa etapa foi realizada por meio de apresentação formal e discussão dos resultados.

Enfim, a equipe de pesquisa desenvolveu um texto inicial descritivo do caso estudado e passou a sistematizá-lo. O texto inicial foi submetido novamente à empresa para validação e verificação de aspectos de confidencialidade, compilado no formato de relatório de pesquisa e disponibilizado para o PMO, os gerentes de projeto e a diretoria da área.

\section{Estudo de caso}

O estudo de caso está apresentado da seguinte forma: primeiramente é descrita uma caracterização geral da empresa sumarizando seu histórico, estratégia de atuação e sua estrutura organizacional, especialmente relacionada ao papel do PMO; em seguida, são apresentados os estágios pelos quais o PMO passou ao longo dos 13 anos; posteriormente são discutidas as funções do PMO sob um enfoque comparativo entre os estágios com base na literatura; enfim, são apresentados dados quantitativos relacionados ao lead-time dos projetos nos estágios e outros elementos quantitativos relacionados ao desempenho do PMO.

\subsection{Caracterização da empresa}

A empresa pesquisada está localizada em um polo tecnológico no interior de São Paulo. Completou, em 2012, 25 anos de história, tendo sido pioneira no Brasil no desenvolvimento e fabricação de Laser, e no desenvolvimento de aplicações deste para a área de Oftalmologia. As aplicações militares do Laser fizeram com que a empresa se aproximasse do Centro Tecnológico da Aeronáutica (CTA) ainda nos anos 1990. Dessa parceria, surgiram aplicações para subsistemas utilizados na área de Defesa. A proximidade com o Instituto Nacional de Pesquisas Espaciais (INPE), por meio dos relacionamentos construídos junto ao CTA, fez com que, em 2004, a empresa se tornasse uma das principais fornecedoras do Programa Espacial Brasileiro, com o desenvolvimento de câmeras de monitoramento ambiental.

A empresa compõe-se de quatro diretorias: filmes finos, pesquisa e desenvolvimento, diretoria comercial e diretoria de manufatura. Cada diretoria tem como diretor um dos sócios proprietários da empresa. A diretoria de "pesquisa e desenvolvimento" (P\&D) é responsável pelo projeto dos equipamentos médicos, aeroespaciais ou militares. Ela é composta pelo PMO pesquisado, por um grupo de engenharia formado por engenheiros mecânicos, eletrônicos, de software e físicos e por um grupo de montagem especializada, composto por técnicos em eletrônica e mecânica, responsável pela integração dos equipamentos de defesa desenvolvidos e pela montagem dos protótipos em geral. As diretorias comercial, de filmes finos e de manufatura são prestadoras de serviços para a diretoria de $\mathrm{P} \& \mathrm{D}$, sendo tais serviços realizados via escritório de projetos. Ou seja, o PMO é a interface formal entre a diretoria responsável pelos projetos e as demais áreas da empresa, visando à execução.

\subsection{Estágios de evolução do PMO}

O Quadro 1 apresenta uma síntese da evolução identificada no PMO da empresa e caracterizada, segundo o referencial teórico apresentado no artigo. São sumarizados os elementos motivadores das transições em PMO, conforme a Figura 2, à exceção do elemento denominado "resultados" do PMO, discutido mais adiante no artigo. Os elementos motivadores permitiram caracterizar 5 estágios na evolução do PMO estudado. Em seguida, são descritos e analisados cada um desses estágios. 


\begin{tabular}{|c|c|c|c|c|c|c|c|c|}
\hline 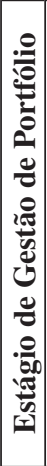 & 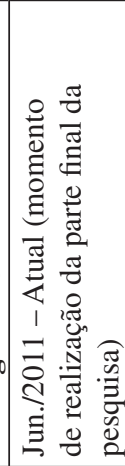 & 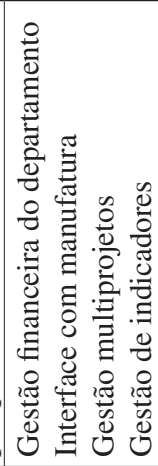 & 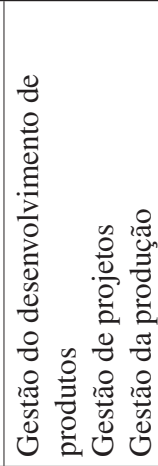 & 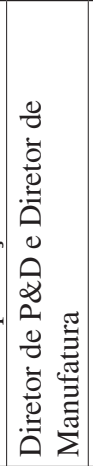 & 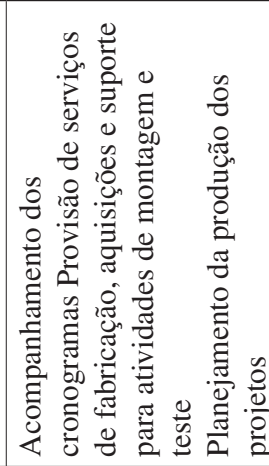 & 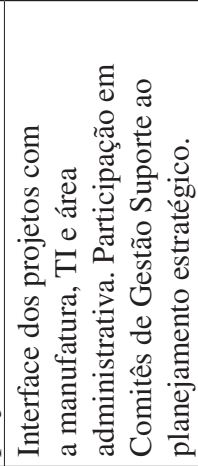 & 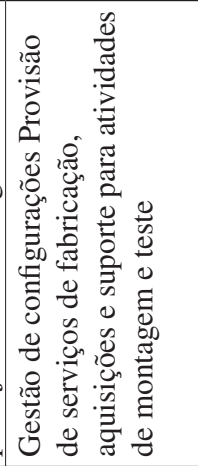 & 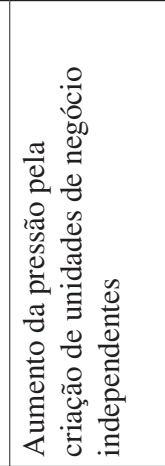 \\
\hline 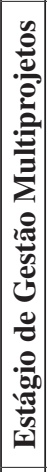 & 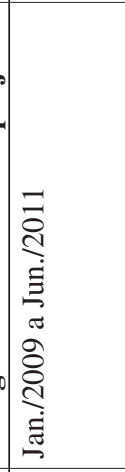 & 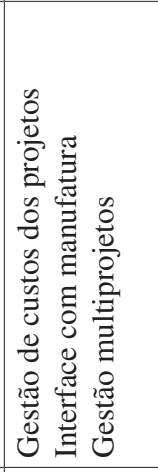 & 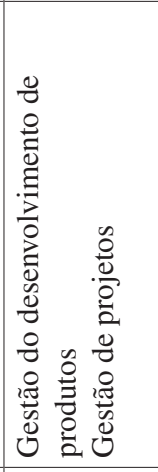 & $\begin{array}{l}0 \\
2 \\
0 \\
0 \\
0 \\
\vdots 0 \\
0 \\
0 \\
\vdots \\
0\end{array}$ & 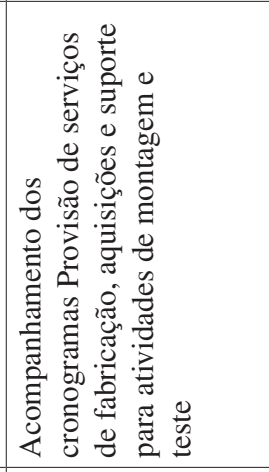 & 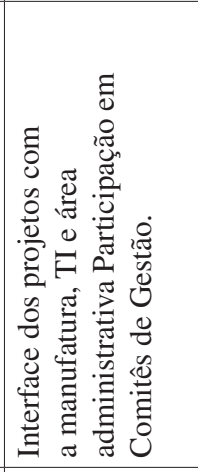 & 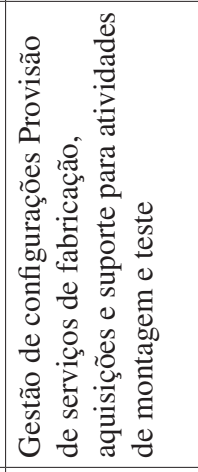 & 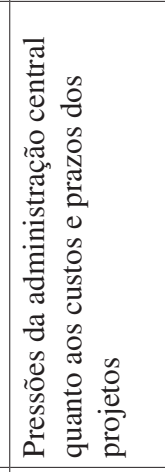 \\
\hline 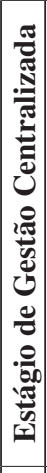 & 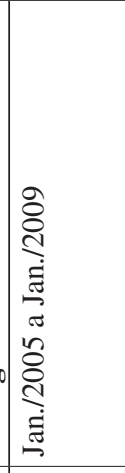 & 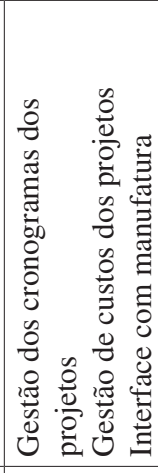 & 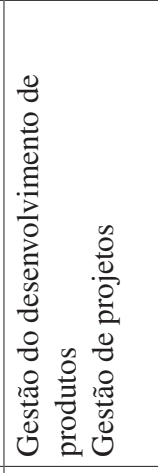 & 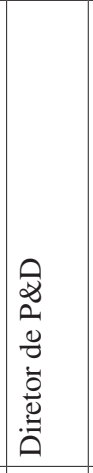 & 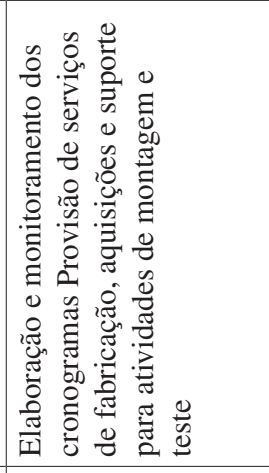 & 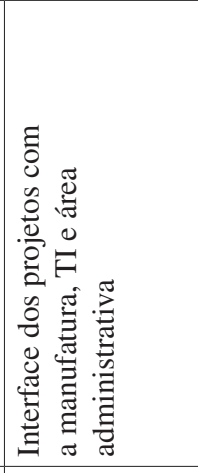 & 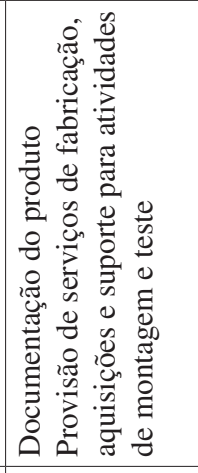 & 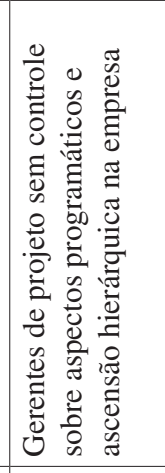 \\
\hline 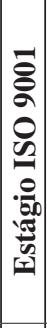 & 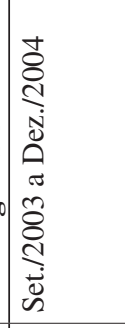 & 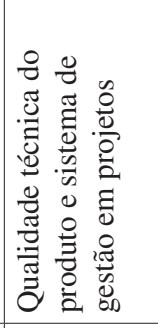 & 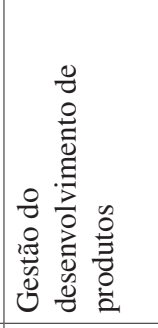 & 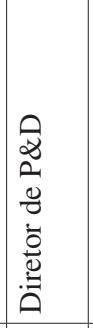 & 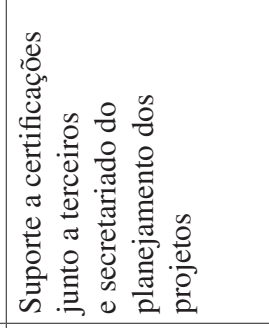 & 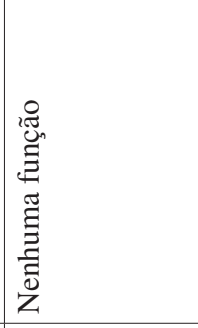 & 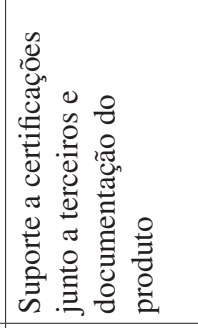 & 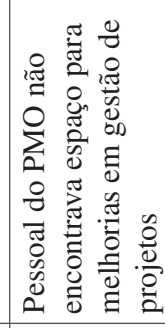 \\
\hline 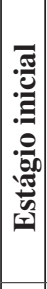 & & 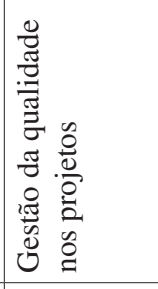 & 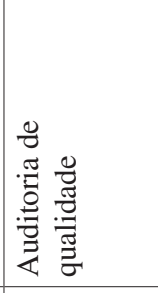 & 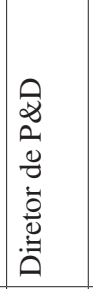 & 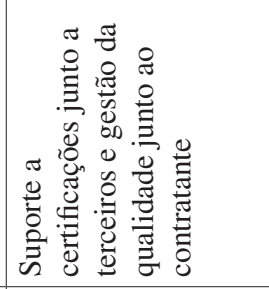 & 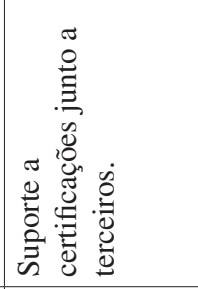 & 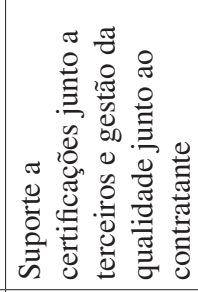 & 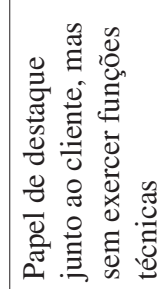 \\
\hline & $\begin{array}{l}0 \\
0 \\
0 \\
0 \\
0\end{array}$ & 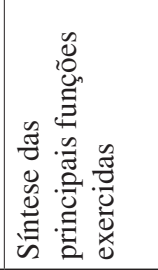 & 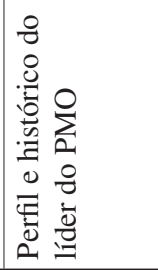 & 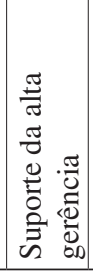 & 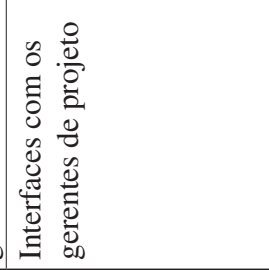 & 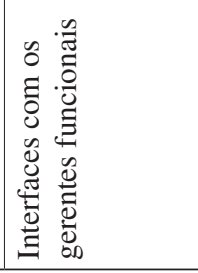 & 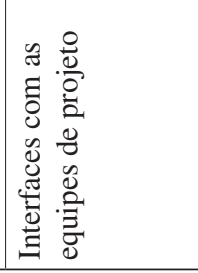 & 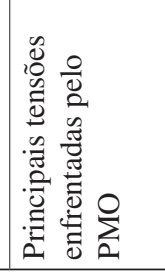 \\
\hline
\end{tabular}




\subsection{Estágio Inicial}

O estágio inicial do Escritório de Projetos, criado na empresa no ano de 1999, pode ser definido como de "conflito técnico". Nele não havia uma estrutura organizacional focada nos aspectos gerenciais dos projetos, mas sim uma estrutura de gestão da qualidade dos projetos, arquitetada em função da demanda de contratantes de projetos do setor de Defesa.

A principal função do PMO era a provisão de serviços técnicos de gestão da qualidade, especialmente quanto às certificações de produto solicitadas pelo contratante. O líder do PMO tinha cargo de Engenheiro e sua especialidade era em auditoria da qualidade. A interface do PMO com os gerentes de projeto e suas equipes era relacionada às demandas de qualidade do contratante. O PMO repassava as demandas para o gerente e equipe de projeto, os quais adequavam os produtos e o supriam com as informações a serem repassadas para o contratante. Similarmente, os gerentes funcionais eram informados sobre demandas que os impactavam e retornavam ao PMO as alterações realizadas em suas áreas funcionais - especialmente manufatura - para que o líder do PMO as informasse ao contratante.

Buscando entender essas características, depreende-se que o conceito da função exercida pelo PMO era o de desonerar as equipes de projeto de demandas de qualidade vinculadas à garantia do produto; aspectos de rastreabilidade; controle de calibrações; codificação de documentos; registros de teste dos protótipos; gestão de configurações; etc. As observações e entrevistas demonstraram que tais atividades eram consideradas não agregadoras de valor e a Diretoria considerava melhor que fossem realizadas por pessoal não diretamente envolvido com os projetos. Como resultado, fortes tensões existiam entre o pessoal de projeto e a equipe do Escritório em função de dois aspectos intrínsecos à arquitetura de atuação do PMO: (1) o PMO não realizava diretamente as atividades de gestão da qualidade e nem exercia gestão sobre a equipe e, portanto, cumpria suas demandas solicitando favores dos membros dos times de projeto ou reportando à Diretoria algum não atendimento de uma entrega demandada ao time ou a algum membro específico; e (2) mesmo não realizando as atividades necessárias à garantia da qualidade, a interface com o cliente era realizada pelo PMO e isso não agradava às equipes que sentiam que sua função era muito operacional. De uma maneira geral, a função exercida era compreendida como não gerando valor para os projetos, o que contribuía para a existência das tensões descritas, corroborando com o perfil de tensão política e de relacionamento com o cliente (HOBBS; AUBRY; THUILLIER, 2008). Por outro lado, a atuação do PMO podia ser considerada reativa e com perfil mais gerencial que técnico - algo pouco valorizado na empresa e que acabava por gerar desgaste entre o Escritório e as equipes.

\subsection{Estágio ISO 9001}

Entre setembro de 2003 e dezembro de 2004, foi realizada uma mudança na gestão do PMO. O líder anterior passou a exercer outra função na empresa. No seu lugar, foi contratado um profissional com perfil mais relacionado à gestão do desenvolvimento de produtos. Pelo perfil, o profissional passou a exercer algumas funções de controle da qualidade do produto demandadas pelos contratantes dos projetos e em parceria com as equipes de projetos. Esse perfil ajudou a mitigar os problemas de relacionamento que existiam entre o PMO e as equipes. Adicionalmente, o PMO incorporou a realização de funções relacionadas à documentação técnica dos produtos, ou seja, desenvolvimento de manuais de usuário, procedimentos de montagem, listas de materiais etc., funções próximas aos engenheiros desenvolvedores.

A característica principal dessa fase, entretanto, foi a certificação ISO 9001 na área de projetos da empresa. Para tal, os processos de trabalho das equipes de projeto passaram por uma sistematização e padronização, tanto em termos de planejamento quanto de monitoramento e controle dos projetos e ainda quanto ao registro de resultados de projeto, com o objetivo de cumprir a cláusula 7.3 da ISO 9001. Passou-se a realizar reuniões periódicas de planejamento e o líder do PMO realizava a consolidação e publicação dos cronogramas discutidos pelas equipes, dando suporte técnico aos gerentes de projeto quanto à utilização de metodologias e softwares de planejamento e controle. Tais atividades demandavam forte interface do PMO com os gerentes de projeto e suas equipes.

A atuação do PMO junto aos gerentes de outras áreas funcionais da empresa passou a ser a transferência das especificações de projeto para os diversos departamentos da empresa. Assim, para o Marketing e Vendas, o PMO desenvolvia os manuais de usuário e discutia a comunicação do produto, já para a Manufatura desenvolvia a lista de materiais e os documentos de montagem e controle da qualidade. Do ponto de vista integrativo, essa fase pode ser considerada uma sensibilização inicial do departamento de projetos da empresa para com as atividades de gestão de projetos propriamente ditas. Considera-se por um lado que as tensões apresentadas no estágio anterior foram mitigadas. Por outro, o perfil de suporte incorporado pelo PMO trazia dificuldades para as equipes de projeto e para o próprio PMO quanto à utilização de melhores práticas em gestão de projetos. Ou seja, a atuação tinha como enfoque mitigar as pressões existentes e manter os projetos em andamento sem que houvesse uma ênfase na proposição de métodos de melhoria em planejamento 
e acompanhamento dos projetos, mas simplesmente mantivesse sua documentação e alinhamento aos procedimentos previamente acordados com a equipe e a Diretoria responsável. Essa sistemática provocava insatisfação por parte dos próprios membros do PMO, os quais não encontravam espaço para a aplicação de melhorias de fato significativas em termos de GP, o que os frustrava profissionalmente, tendo havido no período alta rotatividade do pessoal do escritório.

Pode-se considerar que esse tipo de tensão esteja relacionado com o aspecto de padronização/ flexibilização, conforme descrito em Hobbs, Aubry e Thuillier (2008), porém sob um enfoque contrário ao que normalmente se encontra. Ou seja, no caso pesquisado, a alta flexibilidade com a qual os requisitos da ISO 9001 foram cumpridos e mantidos pelo PMO acabavam impedindo que melhores práticas mais efetivas em GP fossem incorporadas na empresa.

\subsection{Estágio de gestão centralizada}

O estágio seguinte se caracterizou pela centralização de um grande conjunto de funções gerenciais no PMO. A abordagem histórica permitida pelo estudo longitudinal permitiu entender esse estágio baseado no anterior. Ou seja, como havia um ambiente em geral favorável ao PMO, tanto junto às equipes de projeto quanto à Diretoria e às demais áreas funcionais da empresa, e como havia uma demanda do próprio PMO por estabelecer formas de gestão mais alinhadas com as melhores práticas em Gestão de Projetos, criou-se um ambiente propício para introduzir novas ferramentas de GP. Aliado a isso, novos contratos de projetos foram negociados pela empresa, os quais duplicaram o faturamento da firma. Tais contratos demandavam melhor sistemática de gestão de prazos, uma vez que multas contratuais eram previstas para atrasos nas etapas intermediárias e final dos projetos.

Nesse estágio, quanto às principais funções exercidas, o PMO passou a desenvolver cronogramas para os projetos junto às equipes e seus gerentes e a reportá-los para a Diretoria. Nos projetos mais críticos, o PMO passou a monitorar e controlar esses cronogramas semanal e mensalmente. Relatórios gerenciais passaram a ser realizados e reportados ao cliente. Em parceria com o departamento de contabilidade da empresa, passou-se a gerenciar os custos de desenvolvimento numa base mensal. A gestão dos riscos dos projetos passou a ser realizada de forma mais sistemática e padronizada. Nos projetos maiores, os riscos eram analisados tanto do ponto de vista técnico quanto do ponto de vista gerencial. Relatórios de análise de riscos eram consolidados mensalmente pelas equipes e compilados pelo PMO que os reportava aos clientes. Em projetos mais simples, a análise de riscos era incorporada nas atividades de acompanhamento dos cronogramas e custos. A responsabilidade pela qualidade técnica dos produtos que era do PMO desde seu estágio inicial passou a ser compartilhada com as equipes de projeto: um checklist dos requisitos de qualidade do produto era gerado, compilando requisitos do cliente e requisitos normativos e esse checklist era utilizado para a verificação e validação dos projetos. Requisitos funcionais eram de responsabilidade das equipes de projeto e requisitos de segurança eram de responsabilidade do PMO. Auditorias de qualidade eram realizadas pelo PMO ao longo dos projetos, enfocando principalmente a utilização dos procedimentos de gestão previstos. Todas essas funções eram realizadas em estreita interface com os gerentes de projeto.

Quanto à relação com os gerentes funcionais, a atividade de interface realizada pelo PMO junto à manufatura, para a transferência dos novos produtos para a produção, foi incrementada. No estágio anterior, o PMO realizava interface com a produção apenas quando o produto já estava desenvolvido e deveria ser transformado em item de linha. Neste, o PMO passou a realizar a interface com a produção durante todo o processo de desenvolvimento do produto. Para os grandes projetos, essa demanda era vinculada à própria viabilidade de atendimento dos prazos estabelecidos em contrato, pois a manufatura de protótipos continha uma complexidade tal que não ser realizada de maneira sistemática e controlada poderia implicar em atrasos e multas. Para projetos menores, esse passou a ser um procedimento que seus gerentes deveriam seguir. Incluídos nesse elemento estavam atividades de gestão de fornecedores para os suprimentos mais críticos e de codesenvolvimento. Assim, uma estrutura de pessoal, procedimentos e ferramentas de software foi incorporada para dar suporte à interface entre as equipes de projeto, a Manufatura e o PMO.

A visibilidade trazida pela interface dos projetos com a Manufatura e o histórico do estágio anterior do PMO fizeram com que fossem incorporadas outras funções de interface com áreas funcionais: (1) com relação ao departamento de TI, o PMO era responsável pelo controle de acessos do pessoal de projetos às áreas comuns de documentação dos projetos e sistemas de TI utilizados na empresa, assim como pela gestão do sistema de informações de projetos; (2) relativamente a Compras, o PMO era responsável por colocar solicitações de compra e pelo gerenciamento das prioridades de aquisição entre os projetos; (3) com Custos e Controladoria, o PMO era responsável por alocar gastos aos projetos e planejar a estrutura de custos do departamento; (4) com a área de Qualidade, o PMO era responsável pelo sistema de gestão de projetos e pelos requisitos de qualidade dos produtos; (5) com o Planejamento e Controle da Produção (PCP), o PMO era responsável pela estrutura 
de produtos dos equipamentos desenvolvidos; e (6) com a área de Manutenção, o PMO gerenciava a infraestrutura do departamento de projetos solicitando serviços de manutenção de forma centralizada.

Quanto à interface com as equipes de projeto, o PMO reduziu sua atuação de suporte à gestão da qualidade dos projetos, passando a atuar mais fortemente na etapa final do desenvolvimento, na qual era consolidada a documentação do produto. Nesse estágio, passou a ser realizada a gestão das configurações dos produtos desenvolvidos, mediante o uso de listas consolidadas de documentos válidos para os produtos, estruturas de produto alinhadas entre PCP e PMO, e uma base de dados em MS ACCESS $®$, na qual as alterações de produto eram consolidadas e analisadas. Adicionalmente, pode-se considerar que todas as atividades de interface direta com os gerentes de projeto tinham forte impacto sobre as equipes.

Esse estágio durou de janeiro de 2005 a janeiro de 2009. Se o estágio anterior foi marcado por uma atuação cujo maior objetivo do PMO era reduzir as tensões junto aos diferentes atores envolvidos nos projetos, especialmente gerentes e equipes, no estágio de centralização se buscou implementar métodos e ferramentas que aumentassem a produtividade das equipes de projeto, portanto, migrando de um caráter de suporte para uma atuação baseada no controle dos projetos (AUBRY et al., 2010b). Ao longo do tempo, novos projetos foram incorporados ao portfólio da empresa e novas tensões surgiram, especialmente com os gerentes de projeto: (1) por um lado, era responsabilidade dos gerentes o atendimento às especificações técnicas dos produtos, o que em produtos de alta tecnologia exige uma especialização profunda dos profissionais envolvidos e, consequentemente, uma alta valorização de seu trabalho; (2) por outro, os gerentes sentiam que seus projetos eram controlados por um terceiro, o PMO - configurando a tensão definida em Hobbs, Aubry e Thuillier (2008) como "controle sobre a máquina do projeto" -, o qual quanto mais se especializava na gestão de projetos em geral, mais se distanciava das atividades cotidianas de cada projeto em particular; e (3) a visibilidade alcançada pelo PMO na empresa, especialmente por seu gestor, incomodava os demais gerentes quanto às possibilidades de ascensão profissional, especialmente pelo fato de ser uma empresa de médio porte, com poucos níveis hierárquicos e com cargos de diretoria ocupados pelos sócios. Essas tensões levaram o PMO ao estágio seguinte.

\subsection{Estágio de gestão multiprojetos}

O estágio seguinte pode ser entendido como focado em gestão multiprojetos, pois era de responsabilidade do PMO a consolidação dos cronogramas do conjunto dos projetos em desenvolvimento, o planejamento dos orçamentos integrados dos projetos e do departamento de $\mathrm{P} \& \mathrm{D}$, assim como a execução desse orçamento e a definição das prioridades interprojetos quando da alocação de recursos de outras áreas da empresa. $\mathrm{O}$ escritório, ao invés de uma assessoria à Diretoria de $\mathrm{P} \& \mathrm{D}$, passou a ser uma Gerência subordinada a essa Diretoria, assim como os líderes de projeto passaram a ser formalmente denominados como gerentes de projeto na estrutura de cargos da empresa. Atividades de treinamento no sistema de gestão de projetos passaram a ser realizadas pelo PMO, tanto com as equipes como com os gerentes recém-empossados, enfocando as funções tradicionais de GP.

A interface com os gerentes de projeto foi determinada pela pressão exercida pelo aumento dos projetos e pelo poder dos gerentes de projeto, fazendo com que as atividades de gestão de cronograma e reporte da situação dos projetos para os contratantes passassem a ser exercidas pelo gerente de cada projeto. A gestão de riscos também passou a ser realizada pelo gerente e sua equipe, assim como os aspectos relacionados à qualidade do projeto, muito embora a auditoria dos procedimentos de gestão tenha se mantido com o PMO. A responsabilidade pela gestão dos requisitos dos projetos passou a ser dos gerentes de projetos, utilizando o procedimento definido pelo PMO no estágio de "centralização".

Quanto à relação entre o $\mathrm{PMO}$ e as demais áreas funcionais nessa etapa, foram criados comitês de gestão da empresa, e a representação do Departamento de $\mathrm{P} \& \mathrm{D}$ foi incumbida ao PMO, o que reforçava sua função de consolidação das informações e priorização dos recursos entre os projetos. Na interface com as equipes de projeto, reduziu-se o volume de tarefas de documentação de produtos, ficando o escritório mais dedicado às atividades de gerenciamento de configurações e gestão das estruturas de produto junto ao PCP. A função de gestão de custos e planejamento dos orçamentos evoluiu para a aprovação de gastos por parte do PMO para todos os projetos do departamento.

As tensões com os gerentes de projeto foram reduzidas, enquanto a função do PMO se tornou mais especializada e focada na interface do $\mathrm{P} \& \mathrm{D}$ com as demais áreas da empresa. Analisando as dimensões de transição de PMO discutidas por Aubry et al. (2010a), é interessante observar como o caráter de controle foi modificado, passando de um controle mais operacional para um controle mais gerencial e baseado em custos e metas. Um caráter suportivo maior foi incorporado, porém não direcionado aos projetos e sua gestão, mas ao portfólio e à Diretoria da área, o que sugere uma transição na direção do modelo evolutivo de Crawford (2002), passando o PMO de um suporte funcional para uma atividade mais ligada à estratégia mesmo sendo seu reporte ainda a uma diretoria específica. Uma pressão forte 
passou a ser exercida pela administração central quanto à redução dos custos dos projetos e entrega dos produtos nos prazos pré-definidos, sendo essa pressão exercida diretamente sobre a Diretoria de P\&D e o PMO como seu representante intersetorial, configurando uma tensão econômica segundo a classificação de Hobbs, Aubry e Thuillier (2008). Diversas ferramentas de gestão interdepartamental foram confeccionadas nesse estágio de maneira a atender às demandas de comunicação de status por parte dos comitês de gestão e demais atores da alta gerência da empresa.

\subsection{Estágio de gestão de portfólio}

O último estágio verificado na empresa quando da realização das atividades de sistematização e entrevistas finais relacionadas à pesquisa em tela foi caracterizado por uma transição que estava em andamento, na qual a companhia estava sendo dividida em unidades de negócio. A gestão multiprojetos estava sendo enfatizada e uma transição para uma gestão mais profissional e baseada em indicadores de gestão de portfólio estava ocorrendo.

A interação entre o PMO e os gerentes de projeto aumentou em complexidade, pois os gerentes continuaram a ser responsáveis pelos cronogramas de cada projeto e execução de suas tarefas, enquanto o PMO era o responsável formal por monitorar e comunicar ao cliente a situação dos marcos contratuais - para os quais havia pagamentos de eventos e entregas. É importante salientar que essa interface formal junto aos clientes não estava consolidada quando da pesquisa. Indicadores de gestão de prazos, custos e resultados, passaram a ser consolidados mensalmente e discutidos pelo PMO junto à Diretoria e aos gerentes. Uma atividade de suporte ao planejamento estratégico da empresa passou a ser exercida, consistindo da compilação dos indicadores de desempenho dos projetos e da unidade de negócios, assim como o planejamento das ações necessárias à consecução das metas da empresa. Essa atividade também é coordenada pelo PMO, mas realizada em parceria com os gerentes de projeto do departamento de P\&D.

O PMO passou a realizar uma gestão financeira do departamento com base no planejamento já realizado, mas aumentando seu trabalho na interface com os departamentos financeiro e contábil da empresa. Mensalmente, indicadores de estoques e gastos diretos, margens e despesas correntes eram avaliados. A interface com a manufatura incorporou planejamentos de médio e longo prazos, além de melhor sistemática de Planejamento e Controle da Produção no curto prazo. Parte do chão de fábrica passou a ser gerenciado pelo PMO de forma a aumentar a efetividade na manufatura de itens para projetos encomendados ou novos produtos, incorporando programação da produção e controle de chão de fábrica. É importante salientar que o chão de fábrica está subordinado à área industrial da empresa e, portanto, o PMO passou a responder a duas diretorias, embora estivesse ainda alocado formalmente na área de P\&D. Com vendas, finanças e TI, foram sistematizadas atividades de gestão da carteira de forma a compatibilizar as informações de PCP de curto, médio e longo prazo dos projetos, com os pedidos de venda existentes no sistema de informações gerencias da empresa.

A interface do PMO com as equipes de projeto se manteve na gestão de configurações e no gerenciamento da estrutura de produtos. Foi implantado um software específico para o gerenciamento dos custos do projeto - especialmente os custos de mão de obra dos desenvolvedores -, realizado em parceria com o departamento de pessoal da empresa e que tinha forte impacto nas interfaces do PMO com as equipes. Anteriormente a esse estágio, os apontamentos de horas trabalhadas eram realizados por estimativa semanal e mensal. O software implantado demandava que, diariamente, o desenvolvedor alocasse suas horas de trabalho aos projetos e as enviasse ao escritório.

Enquanto as mudanças realizadas para os estágios anteriores tinham uma forte relação com as relações internas do PMO com os gerentes e com a Diretoria da área, o estágio final teve uma motivação oriunda do contexto organizacional da empresa como um todo, visto que, por decisão do Conselho Administrativo - cuja composição havia sido alterada por motivos de aporte financeiro de fundos de investimento -, a companhia foi pensada para ser estruturada por unidades de negócio e isso implicava forte demanda por uma administração mais profissional. Ao invés de contratar pessoal de fora para realizar essas funções, elas foram adicionadas ao escopo do PMO. Assim, a tensão básica que motivou esse estágio do PMO foi ainda a econômica (HOBBS; AUBRY; THUILLIER, 2008) motivada por fatores denominados como mudanças na composição da alta gerência.

\subsection{Quadro comparativo das funções do PMO em cada estágio de sua evolução}

Com base na importância que as funções desempenhadas pelo PMO têm na sua caracterização, realizou-se uma sistematização das atividades apresentadas anteriormente como características de cada estágio do escritório, conforme ilustrado na Tabela 1. Basicamente, todas as funções exercidas pelo PMO, conforme descritas no subitem 4.1, foram agrupadas de acordo com Hobbs e Aubry (2007). Por exemplo, pode-se verificar que os "Serviços técnicos de gestão da qualidade dos projetos" é uma função relativa a "tarefas especializadas", denominadas de 
"ESPECIAL", enquanto que a "Documentação técnica dos projetos" foi categorizada como "aprendizagem organizacional" - "APRENDIZ", na tabela. As ocorrências de cada função nos estágios identificados são apontadas com um "1" na respectiva célula, conforme ilustrado na Tabela 1. A tabela completa das funções do PMO é apresentada no Anexo 1.

Partindo dessa análise, confeccionaram-se gráficos representativos do esforço depreendido pelo PMO quanto aos tipos de funções encontrados por Hobbs e Aubry (2007), conforme a Figura 3, utilizando-se gráficos de radar.

A Figura 3 apresenta a análise das funções exercidas pelo PMO conforme descritas anteriormente. Como o estágio 1 (Estágio Inicial) não tinha fundamento em práticas de gestão de projetos propriamente ditas, mas enfocava a garantia da qualidade dos produtos em desenvolvimento, optou-se por apresentar um mapeamento funcional do PMO dos estágios 2 a 5. Os gráficos apresentam a ocorrência das funções exercidas pelo PMO em cada estágio de acordo com os sete grupos de funções identificados por Hobbs e Aubry (2007), assim como a somatória das funções por estágio. Por exemplo, o estágio 2 apresenta duas atividades de aprendizagem ("APRENDIZ"), duas relacionadas com clientes ("CLIENTES"), uma atividade de desenvolvimento de metodologia de GP ("METODOL") e quatro atividades que podem ser classificadas como funções especializadas ("ESPECIAL"). Ao todo

Tabela 1. Modelo de sistematização das funções desempenhadas pelo PMO.

\begin{tabular}{|c|c|c|c|c|c|c|}
\hline Atividades do Escritório de Projetos & Categorias & Estágio 1 & Estágio 2 & Estágio 3 & Estágio 4 & Estágio 5 \\
\hline $\begin{array}{l}\text { Serviços técnicos de gestão da qualidade } \\
\text { nos projetos }\end{array}$ & ESPECIAL & 1 & 1 & 1 & & \\
\hline Documentação técnica dos produtos & APRENDIZ & & 1 & 1 & & \\
\hline $\begin{array}{l}\text { Desenvolvimento e manutenção dos } \\
\text { procedimentos de gestão de projetos }\end{array}$ & METODOL & & 1 & 1 & 1 & 1 \\
\hline
\end{tabular}

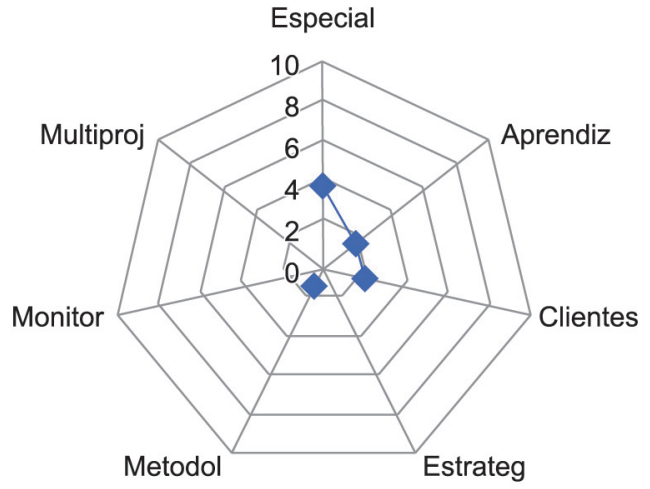

Estágio 2

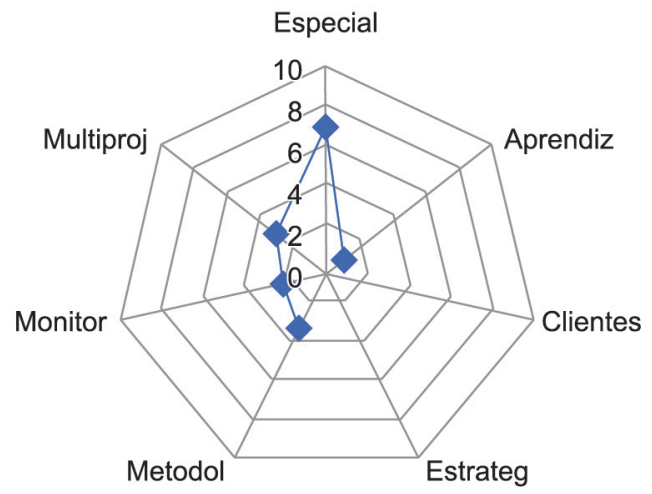

Estágio 4

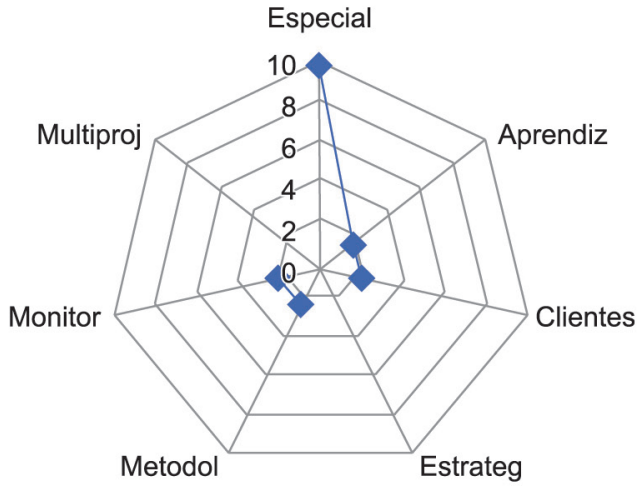

Estágio 3

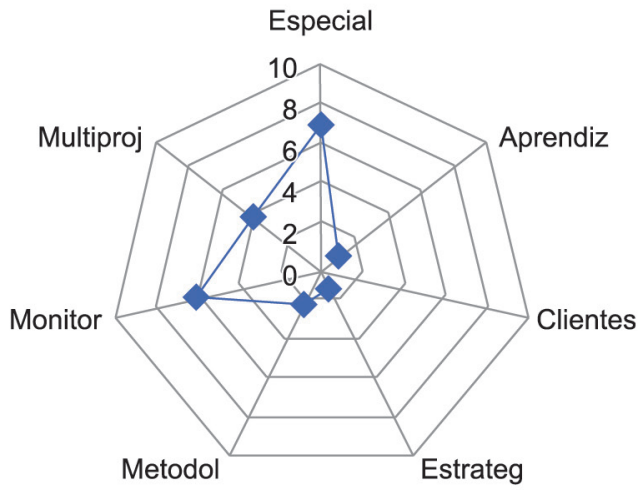

Estágio atual

Figura 3. Categorização das funções exercidas pelo PMO analisado: estágios 2 a 5 . 
são realizadas nove funções diferentes nesse estágio. A lista dessas funções, conforme já mencionado, consta em anexo.

O perfil das funções apresentadas na Figura 3 demonstra, em uma visão geral, que o trabalho do PMO se avolumou ao longo do tempo. Dos sete grupos de funções identificados por Hobbs e Aubry (2007) no estágio 2, eram realizadas atividades apenas de quatro grupos. No estágio 3, passou-se a cinco grupos, o que se manteve no estágio 4 , tendo havido um retrocesso no que tange à gestão de interfaces com os clientes - atividades que passaram a ser exercidas pelos gerentes de projeto como forma de valorização de sua posição na empresa, conforme discutido na seção 5.2. No estágio final, são seis grupos abrangidos pelo PMO.

Outro aspecto demonstrado pelos gráficos de radar é o grau de esforço do PMO em cada grupo. Ao longo dos estágios, vê-se que o grupo de funções denominado "ESPECIAL" foi o que mais mobilizou recursos do escritório, representando inclusive o número máximo encontrado de ocorrências (10 funções no estágio 3 - "gestão centralizada"). O importante é que esse enfoque se manteve do estágio 2 ao final. Isso significa que o PMO tem enfatizado a realização de tarefas que são importantes para a execução dos projetos, mas que, por algum motivo, não são realizadas pelo gerente de projetos e sua equipe, ou por outro ator organizacional. Isso sugere que o PMO atuou em lacunas dos processos necessários à consecução dos projetos, muito embora a motivação para tal não tenha sido abordada no estudo.

Enfim, os gráficos demonstram que a evolução das atividades realizadas pelo PMO gerou um perfil de atuação, no qual funções de "monitoramento e controle" ("MONITOR") e de "gestão multiprojeto" ("MULTIPROJ") passaram a ter grande importância no conjunto de ações desempenhadas, o que demonstra uma atuação mais orientada para controle e voltada para programas e portfólios - conforme a já apresentada classificação de Aubry et al. (2010a) - que de suporte aos projetos. Esse perfil é reforçado pelo início das ações relacionadas ao grupo de "gestão estratégica dos projetos" ("ESTRATEG") no estágio final diagnosticado no PMO. Por outro lado, o gráfico demonstra também que as atividades relacionadas à "metodologia de gestão de projetos" ("METODOL") apresentam um perfil de retração entre os estágios 4 e final, depois de terem sido incrementadas quando comparados os estágios $3 \mathrm{e}$ 4. Com base nos dados analisados, não é possível inferir o porquê, mas vê-se que tanto o grupo "metodologia de gestão de projetos" quanto o grupo "aprendizagem organizacional", funções tradicionais dos PMOs, não são enfatizados no quadro evolutivo do caso aqui estudado.

\subsection{Resultados do PMO ao longo de seus estágios}

Como visto na revisão bibliográfica deste trabalho, os resultados apresentados pelo PMO e pelos projetos são direcionadores do sucesso dos PMOs. Assim sendo, uma das hipóteses do trabalho é a de que tais resultados podem explicar a evolução do escritório, especialmente em ocasiões nas quais ele assumiu novas funções ou funções mais relacionadas com aspectos diretivos e de suporte à alta gerência e não aos gerentes de projeto. Em outras palavras, mudando de "nível" (CRAWFORD, 2002).

De maneira a verificar esse aspecto, foram levantados dados relativos ao desempenho dos projetos que tiveram suporte do PMO desde o estágio 1 ao estágio 5. Tal desempenho foi aferido pelo cálculo do lead-time total dos projetos, o qual, segundo Clark e Fujimoto (1991), juntamente com a produtividade da engenharia e a qualidade do produto, são os principais indicadores de desempenho em projetos de novos produtos. Dados da quantidade e do lead-time dos projetos ao longo dos estágios do PMO são apresentados na Figura 4. Veem-se, na figura, dois gráficos ao longo dos estágios do PMO estudado. O gráfico de barras apresenta o número de projetos gerenciados em cada estágio, considerando a data de início do projeto como base para identificar o estágio do PMO, no qual ele se enquadra. O gráfico em linha caracteriza o lead-time médio dos projetos em cada estágio. Apresenta-se ainda, a quantidade em meses de cada estágio.

Observa-se que a curva de lead-time ao longo dos estágios do PMO é fortemente decrescente. Em nenhum dos estágios identificados, houve uma piora

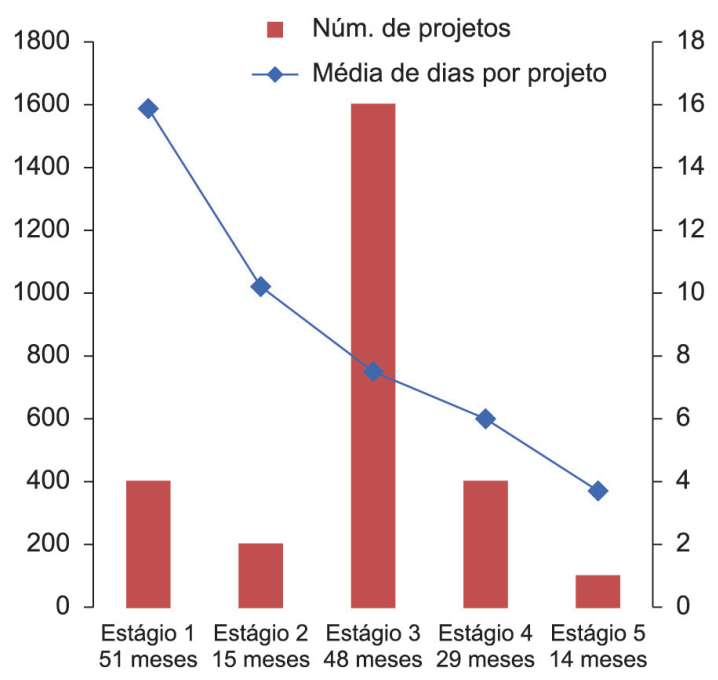

Figura 4. Lead-time total dos projetos ao longo dos estágios do PMO. Estágio 1 - inicial; estágio 2 - ISO 9001; estágio 3 - centralização no PMO; estágio 4 - gestão multiprojetos; estágio 5 - gestão de portfólio. 
nos lead-times médios dos projetos, o que demonstra que a evolução da metodologia de gestão de projetos, envolvendo os gerentes e o escritório, tem trazido efeitos positivos para a empresa. Mesmo no estágio 3 , no qual foram concluídos 16 projetos ao longo de 48 meses, houve redução significativa no lead-time quando comparado com o estágio 2. Como o estágio 5 (gestão de portfólio) estava em andamento quando da pesquisa e tinha pouco mais de um ano de duração e apenas um projeto concluído, considera-se que o dado de evolução no lead-time nesse estágio não pode ser conclusivo, sendo coerente com os anteriores, entretanto. Ou seja, ao menos no projeto concluído se manteve o padrão histórico.

$\mathrm{O}$ outro aspecto de resultado mencionado na literatura tem relação com os resultados específicos do PMO. Nesse sentido, verificou-se que o escritório mantinha uma sistemática de aferição de indicadores relacionados a lead-times das atividades que gerenciava. A apresentação detalhada desses indicadores foge ao escopo do artigo, mas pode ser sumariamente representada pelo seguinte: (1) o lead-time médio de peças fabricadas para protótipos caiu de cerca de 110 dias para um patamar de 10-15 dias para cada peça demandada para os protótipos e projetos contratados; (2) o lead-time médio de itens comprados para os protótipos e projetos contratados caiu de cerca de 200 dias para menos de 50 dias; e (3) o lead-time das alterações na configuração e documentação dos projetos desenvolvidos caiu de cerca de 50 dias para uma semana.

A literatura enfatiza que a quantificação dos resultados do PMO não é simples de ser feita, em função da multiplicidade de funções desempenhadas pelos escritórios (HOBBS; AUBRY, 2007). Para o PMO analisado neste texto, essa situação se aplica. Por exemplo, como aferir o desempenho da consolidação dos cronogramas multiprojeto ou da centralização das ações de manutenção necessárias ao departamento de P\&D da empresa? De uma maneira geral, considera-se que o resultado do projeto em termos de prazo é mais significativo que aferições parciais sobre processos específicos do escritório. Considera-se ainda que os resultados alcançados pelos produtos representem, adicionalmente, indicadores mais precisos do desempenho da ação gerencial relacionada aos projetos. Essa análise, entretanto, foge também ao escopo do artigo.

Enfim, considera-se que a estrita análise dos dados apresentados nesta seção permite verificar que o desempenho dos projetos se manteve exitoso ao longo do período compreendido na pesquisa e em todos os estágios de evolução do escritório.

\section{Análise integrada dos dados levantados em campo}

O estudo exploratório apresentado neste texto permitiu verificar que, ao longo de 13 anos, houve quatro transições no perfil da atuação do escritório dentro do contexto dos projetos desenvolvidos pela firma. Essas transições foram caracterizadas a partir das funções desenvolvidas pelo escritório e de suas interfaces com os gerentes de projeto, as equipes de projeto e os gerentes funcionais. Pelo estudo, os aspectos de "perfil e histórico do líder do PMO" e de "suporte da alta gerência" não puderam ser usados para analisar essas transições, pois se mantiveram constantes ao longo dos estágios, o que, todavia, demonstra que, mesmo sem que variassem esses elementos, houve transições no escritório.

A principal categoria do quadro teórico, que permitiu explicar as transições por meio de uma lógica empírico-dedutiva, foi o aspecto das tensões às quais o PMO estava sujeito em cada estágio. Mesmo os resultados apresentados pelo PMO não tiveram tanto impacto, pois as transições ocorreram e impactaram nas funções desempenhadas pelo escritório mesmo sendo os resultados - dos projetos e do próprio escritório - bastante positivos. A Figura 5 apresenta uma visão integrada de como os elementos pesquisados podem ser entendidos com base no estudo.

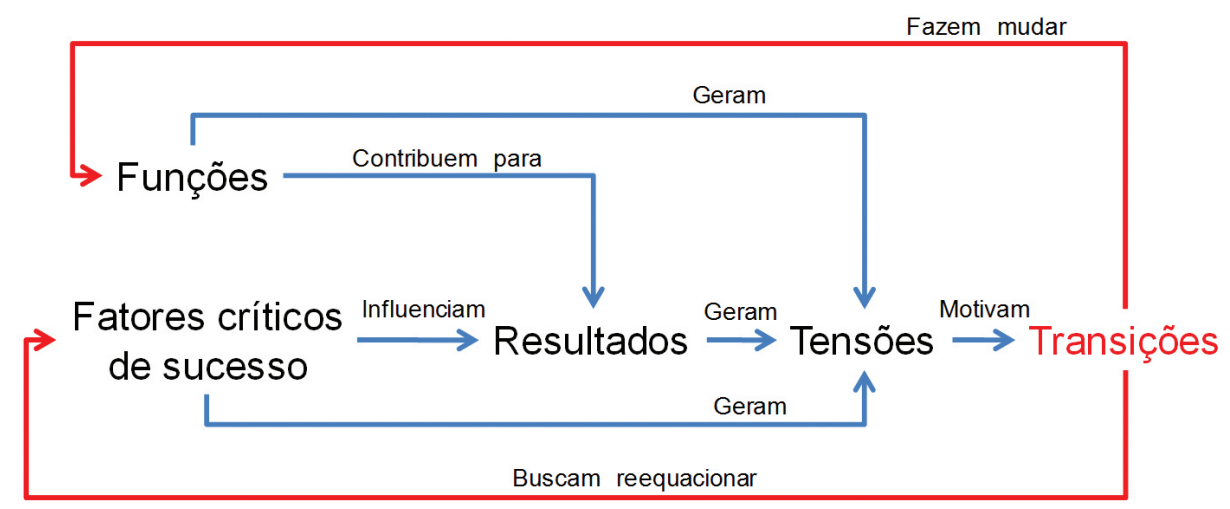

Figura 5. Quadro interpretativo dos dados levantados nesse estudo. 
Primeiramente, é importante ressaltar que o caráter de generalização do estudo é limitado em função da amostra ser composta de um único PMO em uma única empresa. Portanto, o que será exposto a seguir deve ser visto como hipótese a ser testada em estudos mais abrangentes e não como teoria consolidada. Dito isto, o estudo exploratório permitiu verificar que as transições têm como único elemento que diretamente as motiva, as tensões experimentadas pelo PMO ao longo de seus estágios intermediários. Observou-se que nem as funções isoladamente explicam porque há mudança, nem qualquer dos fatores críticos analisados ou mesmo os resultados dos projetos e/ou PMO a explicam. Essas variáveis geram tensões entre os atores envolvidos e as tensões atuam motivando as transições.

Isso pôde ser verificado quando primeiramente a própria insatisfação do pessoal do PMO levou à transição do estágio "ISO 9001" para o de "CENTRALIZAÇÃO". A seguir, as tensões entre o PMO, os gerentes de projeto e as equipes de projeto levaram à transição para o estágio "GESTÃO MULTIPROJETOS". Posteriormente, tensões mais impostas por gerentes funcionais e pela alta direção impulsionaram a mudança para o estágio de "GESTÃO DE PORTFÓLIO”. Todas essas transições ocorreram em um ambiente no qual os resultados dos projetos e do PMO eram bastante positivos em relação ao indicador de desempenho analisado na pesquisa.

Voltando ao quadro, as transições, por sua parte, se concretizam na forma de mudanças nas funções exercidas pelo PMO, sendo sua lógica constitutiva basicamente vinculada ao equacionamento dos fatores críticos de sucesso. Ou seja, no caso estudado ficou claro que as funções do PMO foram incrementadas ou suprimidas com base nas tensões entre os atores. Como o respaldo e vínculo com gerentes de projeto, gerentes funcionais, equipes de projeto e demais atores organizacionais são fatores críticos de sucesso do PMO, mitigar tensões entre esses atores e o PMO demonstrou ser mais importante que manter os resultados positivos. Explicando melhor, os dados de lead-time demonstram que houve, em todos os estágios, uma redução no tempo de finalização dos projetos. Obviamente que o risco de prejudicar esse indicador passou a ser considerado quando da redefinição das funções do PMO nos projetos. Entretanto, o caso demonstra que mitigar as tensões entre os atores foi considerado mais importante que o risco de piorar os lead-times; e as funções exercidas pelo PMO foram efetivamente alteradas em todas as transições de estágio analisadas.

$\mathrm{O}$ aspecto das funções traz outro elemento à discussão, quando se verifica que é esse o elemento do modelo analítico que materializa a ação do PMO nos projetos, contribuindo efetivamente para os resultados destes e do próprio PMO. Já os fatores críticos podem ser entendidos como elementos que influenciam os resultados alcançados pelos projetos e pelo PMO, obviamente que considerando o contexto do estudo. Diversos trabalhos já demonstram que as equipes de projeto, os gerentes de projeto e funcionais etc., têm impacto significativo nos resultados. A contribuição aqui, entretanto, é na confecção de uma hipótese de que tais atores - quando analisado o resultado sob o enfoque dos PMOs - influenciam os resultados, porém nenhum deles os determina, visto que, mesmo que haja insatisfação e tensões entre o PMO e esses atores, resultados positivos ocorrem. É importante frisar, enfim, que os dois fatores críticos que não tiveram impacto sobre as transições do PMO analisado, uma vez que não sofreram mudança entre os estágios - suporte da alta gerência e perfil do líder do PMO -, não podem ser, com base no estudo, descartados quanto à sua influência sobre os resultados conseguidos. Eles apenas, no estudo, não geraram as tensões que impulsionaram as transições verificadas.

A questão dos resultados é um aspecto não muito simples de ser entendido. O ponto de partida é que, independente dos resultados apresentados, houve mudança no PMO. Portanto, este é um aspecto que não impacta diretamente na transição. A relação entre os resultados e as funções e entre eles e os fatores de sucesso foram analisadas. O entendimento construído em função dos dados empíricos é o que está exposto na figura pela relação "resultado" -> gera -> "tensões". A explicação é que, à medida que o PMO demonstra ser efetivo nas suas funções e os projetos são exitosos, os resultados apresentados passam a gerar uma tensão quanto à expectativa de crescimento na empresa. Esse crescimento, no PMO, pode estar relacionado à execução de funções mais substantivas conforme ocorre no caso, em que, paulatinamente, as funções de monitoramento e controle, de gestão multiprojetos e de gestão estratégica foram sendo incorporadas. Mas pode estar relacionado também ao crescimento dos atores na hierarquia corporativa, pois parte das tensões experimentadas pelo PMO era consequência direta de disputas políticas entre os gerentes do departamento, tanto gerentes de projeto entre si, como entre estes e o gerente do PMO, quanto à ascensão na hierarquia. Esse conflito político se manifestava no cotidiano por meio da disputa entre os gerentes para se beneficiar - com novas funções, novos papéis, melhor remuneração, aumento do efetivo sob sua gestão etc. - dos resultados positivos gerados pelos projetos. No quadro teórico explicativo a que se chegou, isso significa que os resultados geravam tensões entre os atores envolvidos nos projetos e o $\mathrm{PMO}$, as quais passavam a demandar mudanças que implicavam transições no escritório.

Enfim, quando da análise das funções do PMO estudado (seção 5.3) observou-se que entre o estágio 
2 e o estágio 5 mais funções foram desempenhadas, e estas foram mais bem distribuídas entre os grupos propostos por Hobbs e Aubry (2007). Se considerarmos a relação sugerida na Figura 5, podemos supor que uma distribuição melhor das funções ao longo desses grupos tem potencial de gerar melhores resultados para os projetos sob influência de um determinado $\mathrm{PMO}$, o que, no caso pesquisado, de fato ocorreu.

\section{Considerações finais}

Os escritórios de projeto surgiram como entidades dedicadas a suportar o gerenciamento de grandes e/ ou complexos projetos em organizações dedicadas a estes. Atualmente, entretanto, escritórios têm sido usados nas mais diversas organizações e com uma grande diversidade de funções. A literatura aponta o fato de essas estruturas estarem constantemente sujeitas a transições. Este artigo, por meio de um estudo de caso longitudinal, buscou verificar as transições ocorridas em um PMO ao longo dos 13 anos de sua atuação em uma empresa desenvolvedora de novos produtos. As considerações finais relacionadas à pesquisa apontam contribuições para a teoria, para a prática e limitações do trabalho com sugestões de pesquisas futuras.

\subsection{Contribuições para a teoria}

Pode-se considerar que o primeiro elemento da pesquisa em tela que representa uma contribuição para a teoria é a identificação do quadro teórico envolvido no que a literatura vem denominando "transições" em escritórios de projeto. Nesse sentido, buscaram-se mapear os fatores identificados na literatura como críticos ao sucesso dos PMOs, assim como suas funções, resultados e tensões sob as quais atua. Considerou-se que esses elementos poderiam de alguma forma explicar as transições. E, de fato, foi possível entender e reconstituir a trajetória das transições no PMO pesquisado utilizando tal quadro teórico, algo a ser utilizado em outras situações de maneira a verificar sua aplicabilidade.

Observou-se que as transições ocorreram mais em função de fatores internos à empresa do que relativo a fatores ambientais. Os fatores internos que motivaram as transições têm relação com diversos atores e não apenas a alta direção, contrariamente ao sugerido na literatura. Especialmente, as relações com gerentes de projeto, equipes e gerentes funcionais foram decisivas para as transições. Dito isto, observou-se que a alta direção buscou atuar mais arbitrando as tensões entre estes atores do que impondo novos formatos. Apenas no estágio final houve um perfil mais impositivo na atuação da alta gerência. Pode-se considerar que a arbitragem tinha, ao longo do tempo, o objetivo de manter um clima organizacional positivo para os projetos, buscando também impulsionar as práticas de gestão de projetos conduzidas pelo PMO em direção a uma gestão de portfólio mais sistematizada.

Todos os tipos de tensões identificadas na literatura ocorreram no PMO pesquisado. Observou-se que as tensões políticas, de controle sobre o projeto, de relacionamento com o cliente interno e da dicotomia padronização/flexibilização tiveram forte impacto nas transições cujo principal objetivo foi abordar o conflito entre os atores envolvidos na gestão de projetos da empresa e o PMO. Já as tensões de caráter econômico e o relacionamento com os clientes externos foram os motivadores para as transições que impulsionaram o desempenho técnico das práticas de gestão de projetos e de portfólio. Observou-se, enfim, que há tensões não mapeadas na literatura que dizem respeito à disputa pelos benefícios advindos do sucesso dos projetos. Os resultados alcançados pelos projetos trazem visibilidade para os atores envolvidos neles. Os atores buscam transformar a visibilidade em maior poder, melhor remuneração ou ambos. Assim, a propriedade pelo sucesso do projeto implica em tensão política entre os atores internos à empresa.

A literatura menciona que os PMOs devem buscar agregar novos valores à empresa ao longo do tempo, à medida que as práticas desenvolvidas são consolidadas. $\mathrm{O}$ caso estudado permitiu verificar que o PMO buscou agregar valores pela realização de funções necessárias aos projetos e que não eram realizadas por nenhum dos demais atores da empresa. Objetivou fechar lacunas nos processos organizacionais. Sejam lacunas relacionadas às áreas de conhecimento da gestão de projetos, sejam lacunas relativas à gestão do portfólio. Não foram encontradas funções relacionadas ao conceito de programa.

Enfim, parte da literatura relacionada aos escritórios de projetos, sugere que há um padrão evolutivo dividido em níveis e que explica as funções dos PMOs. Eles estariam vinculados a projetos específicos, depois a unidades de negócio e, por fim, à estratégia corporativa. Observou-se, no caso estudado, que ao longo dos 13 anos, um padrão evolutivo similar ocorreu. Porém, há que se considerar que as transições ocorridas figuraram mais dentro de um mesmo nível do que na ascensão de um nível a outro. Além disso, as transições entre níveis tiveram relação com tensões econômicas ou relacionadas aos clientes externos, enquanto as transições no mesmo nível se relacionavam com tensões internas entre os atores envolvidos nos projetos, conforme já mencionado. Em geral, o caso aponta para uma dinâmica bem diferenciada de uma perspectiva evolucionista. Nada permitiu observar, por exemplo, que um retorno de uma função mais vinculada à gestão de portfólio para um perfil mais focado em um projeto específico - caracterizando um retorno de nível 3 para nível 1 - não seria possível. Observa-se, enfim, que o 
padrão das funções exercidas tem relação com outros aspectos da estrutura organizacional, da estratégia da empresa, do crescimento das áreas de negócio e mesmo da evolução da carreira dos principais envolvidos com os projetos, incluindo o PMO, seus participantes e gerentes.

\subsection{Contribuições para a prática}

A origem dos projetos e, portanto, a necessidade de gerenciá-los é tão antiga quanto os primeiros grandes empreendimentos da humanidade. Hoje, todavia, projetos são cada vez mais comuns. Os formatos tradicionais de gestão que separavam os métodos de gestão das organizações que tradicionalmente atuam em mercados de alto volume com linhas de produção dedicadas de um lado, e organizações orientadas a projetos de outro, carecem de ferramentas e estruturas organizacionais que permitam coadunar essas realidades que cada vez mais ocorrem concomitantemente numa empresa. A primeira implicação prática relacionada ao artigo é que o caso demonstrou que os PMOs podem ser utilizados pela alta gerência como estruturas flexíveis que podem sanar lacunas existentes nos processos da empresa. Essa flexibilidade pode ser de grande valia quando as empresas de alto volume buscam reforçar sua atuação em projetos ou quando empresas de projetos buscam sistematizar processos mais repetitivos.

Gerentes de escritórios de projeto podem utilizar os resultados aqui apresentados para pensar sua própria forma de atuação nas organizações em que atuam. Por um lado, alinhar a atuação do escritório com o trabalho dos gerentes de projeto e funcionais. Por outro, atender aos anseios da alta gerência e facilitar o trabalho das equipes de projeto. Observou-se que perfis de atuação mais centralizados no PMO, embora impulsionem a utilização de técnicas e melhores práticas de gestão de projetos, criam um ambiente de muita tensão envolvendo o escritório, o que pode resultar em deterioração do clima organizacional devendo, portanto, ser evitado ou utilizado com muita cautela.

Verificou-se que, ao longo do tempo, o PMO foi acumulando funções em todos os grupos e, quando cruzados esses dados com os resultados dos projetos, observou-se um desempenho cada vez melhor em termos de prazos. Sugere-se, portanto, que as organizações busquem desenhar seus escritórios de projeto de maneira que todos os grupos de funções dos PMOs sejam trabalhados em paralelo pelo escritório. Especialmente a área relacionada a treinamento, aconselhamento e formação de competências em GP deve ser enfatizada, pois, ao longo do tempo, a manutenção das práticas estabelecidas pelo escritório depende de haver pessoal na empresa qualificado para tal. Não há como o PMO evoluir para níveis de atuação mais estratégicos se não houver quem mantenha os resultados conquistados nos níveis anteriores - projeto e unidade de negócios.

Enfim, considera-se que a estruturação de um escritório de projetos com o formato discutido neste texto depende de haver no PMO o conhecimento adequado e necessário para entender os desafios dos projetos em execução na firma, assim como as lacunas apresentadas pelos processos organizacionais para que tais projetos sejam exitosos. Em outras palavras, o PMO deve ser o centro de competência em gestão de projetos e no que isso implica para a empresa. Portanto, a liderança e os membros do PMO devem dominar as melhores práticas em GP de maneira a construir os processos necessários para que elas sejam incorporadas no cotidiano da empresa. O caráter específico da firma e seus projetos, entretanto, trazem a necessidade de que o PMO conheça bem $o$ aspecto técnico do que a empresa realiza. Apenas coadunando o caráter de GP com esse aspecto técnico é que o PMO vai poder visualizar e atuar nas lacunas deixadas pelos processos existentes na empresa em dado momento.

\subsection{Limitações e trabalhos futuros}

A principal limitação deste trabalho é ser um estudo de caso. Portanto, não há como generalizar os resultados e reflexões analisados no texto.

Do ponto de vista técnico, a pesquisa poderia ter agregado alguns elementos adicionais ao quadro teórico. Por um lado, considera-se que, mais que verificar se os fatores críticos de sucesso do PMO foram atendidos ou não, deve-se analisar em que grau eles foram atendidos. Embora o estudo em tela tenha analisado esses fatores críticos sob uma abordagem qualitativa e histórica, pesquisas futuras poderiam criar estágios de atendimento desses fatores críticos de maneira a realizar uma análise comparativa entre PMOs diferentes. Como categorizar esses fatores críticos é algo a aprofundar para estudos futuros. Ainda do ponto de vista técnico, embora a pesquisa aqui relatada tenha abordado os resultados dos projetos em termos de prazo, nada garante que um projeto de produto concluído em menos tempo seja exitoso. O êxito está, de fato, no resultado do produto do projeto no mercado. Trazer esses dados à tona $\mathrm{e}$ relacioná-los com as transições ocorridas no PMO seria algo muito relevante para a estruturação dos escritórios de projetos.

Dito isto, a partir do entendimento do que compunha cada estágio identificado, assim como dos dados relacionados ao desempenho dos projetos e do escritório, foi possível criar um quadro esquemático que permitiu compreender os dados empíricos. Considera-se que esse quadro teórico possa ser 
utilizado em pesquisas futuras como hipóteses a serem testadas e refinadas para compreender a lógica de evolução dos PMOs e, quem sabe, a partir deles, das organizações que se baseiam em projetos para cumprir seus objetivos.

Enfim, trabalhos futuros buscarão agregar ao quadro conceitual o aspecto da maturidade em GP e seu impacto sobre as transições nos escritórios de projeto. A literatura sugere que a atuação dos escritórios de projeto é influenciada pela maturidade em GP da empresa, que, por sua vez, impacta as funções dos escritórios e assim por diante. Quais funções são impulsionadas pela maturidade? Que transições ela beneficia? Que tensões surgem para que ela ocorra e impacte os escritórios? Considera-se que tais questões podem ter alto impacto na forma pela qual os PMOs podem e devem ser estruturados para exercer seu papel de potencializar as práticas de GP e os resultados dos projetos nas empresas.

\section{Agradecimentos}

Os autores gostariam de deixar um profundo agradecimento aos revisores deste artigo. Seu trabalho minucioso fez o texto final ser muitas vezes superior ao que inicialmente foi desenvolvido, seja em aspectos de conteúdo, de explicitação da ideia central do texto, quanto à forma, questões pontuais etc. Independente do resultado final, nosso muito obrigado.

Agradecemos também à OPTO ELETRÔNICA S.A., uma empresa inovadora que permitiu que este estudo fosse concretizado, além de ter proporcionado a um dos autores uma vivência profunda sobre a temática aqui desenvolvida, nunca o tendo desmotivado à manutenção de uma atividade acadêmica paralela.

\section{Referências}

ALVES, R. O. et al. Melhores práticas em implantação de escritório de gerenciamento de projeto: desenvolvimento de referenciais de sucesso. Production, v. 23, n. 3, p. 582-594, 2013.

AUBRY, M.; HOBBS, B. A fresh look at the contribution of project management to organizational performance. Project Management Journal, v. 42, n. 1, p. 3-16, 2011. http://dx.doi.org/10.1002/pmj.20213

AUBRY, M. et al. Identifying forces driving PMO changes. Project Management Journal, v. 41, n. 4, p. 30-45, 2010a. http://dx.doi.org/10.1002/pmj.20191

AUBRY, M. et al. Project management offices in transition. International Journal of Project Management, v. 28, n. 8, p. 766-778, 2010b. http://dx.doi.org/10.1016/j. ijproman.2010.05.006

AUBRY, M.; HOBBS, B.; THUILLIER, D. A new framework for understanding organizational project management through the PMO. International Journal of Project Management, v. 25, n. 4, p. 328-336, 2007. http:// dx.doi.org/10.1016/j.ijproman.2007.01.004
BARBALHO, S. C. M. et al. Rompendo obstáculos para a implantação de escritório de projetos em empresa de base tecnológica. Gestão \& Produção, v. 16, n. 3, p. 435-449, 2009. http://dx.doi.org/10.1590/ S0104-530X2009000300010

BARDIN, L. Análise de conteúdo. Tradução de Luís Antero Reto e Augusto Pinheiro. Lisboa: Edições 70, 1979.

BREDILLET, C. N. Mapping the dynamics of the project management field: project management in action (part 6). Project Management Journal, v. 41, n. 2, p. 2-4, 2010. http://dx.doi.org/10.1002/pmj.20177

CARVALHO, M. M. et al. Equivalência e completeza: analise de dois modelos de maturidade em gestão de projetos. Revista de Administração da Universidade de São Paulo, v. 40, n. 3, p. 289-300, 2005.

CLARK, K. B.; FUJIMOTO, T. Product development performance: strategy, organization and management in the world auto industry. Boston: Harvard Business School Press, 1991.

CRAWFORD, L. The strategic project office: a guide to improving organizational performance. New York: Marcel Dekker, 2002.

CRAWFORD, L. Developing organizational project management capability: theory and practice. Project Management Journal, v. 36, n. 3, p. 74-97, 2006.

EISENHARDT, K. M. Building theories from case study research. Academy of Management Review, v. 14, n. 4, p. 532-550, 1989.

GODOY, A. S. Introdução à pesquisa qualitativa e suas possibilidades. Revista de Administração de Empresas, v. 35, n. 2, p. 57-63, 1995. http://dx.doi.org/10.1590/ S0034-75901995000200008

HEDEKER, D.; GIBBONS, R. D. Longitudinal data analysis for biomedical and behavioral sciences. New Jersey: John Wiley \& Sons, 2006. (Wiley Series in Probability and Statistics).

HOBBS, B.; AUBRY, M. A multi-phase research program investigating project management offices (PMO): the results of phase 1. Project Management Journal, v. 38, n. 1, p. 74-86, 2007.

HOBBS, B.; AUBRY, M.; THUILLIER, D. The project management office as an organisational innovation. International Journal of Project Management, v. 26, n. 5, p. 547-555, 2008. http://dx.doi.org/10.1016/j. ijproman.2008.05.008

KARLSSON, C.; AHLSTRÖM, P. Change processes towards lean production: the role of the remuneration system. International Journal of Operations \& Production Management, v. 15, n. 11, p. 80-99, 1995. http://dx.doi. org/10.1108/01443579510102918

MARTINS, A. P. et al. Implantação e consolidação de escritório de gerenciamento de projetos: um estudo de caso. Revista Produção, v. 15, n. 3, p. 404-415, 2005. http://dx.doi.org/10.1590/S0103-65132005000300010

MAXIMIANO, A. C. A.; ANSELMO, J. Escritório de gerenciamento de projetos: um estudo de caso. Revista de Administração, v. 41, n. 4, p. 394-403, 2006.

MENARD, S. Longitudinal Research. Newbury Park: Sage, 2002. 
MULLALY, M. Longitudinal analysis of project management maturity. Project Management Journal, v. 36, n. 3, p. 62-73, 2006.

PELLEGRINELLI, S.; GARAGNA, L. Towards a conceptualisation of PMO as agents and subjects of change and renewal. International Journal of Project Management, v. 27, n. 7, p. 649-656, 2009. http:// dx.doi.org/10.1016/j.ijproman.2008.12.001

RODRIGUES, I.; RABEQUINI JÚNIOR, R.; CSILLAG, J. M. Os escritórios de projetos como indutores de maturidade em gestão de projetos. Revista de Administração da Universidade de São Paulo, v. 41, n. 3, p. 273-287, 2006.

SERVA, M.; JAIME JÚNIOR, P. J. Observação participante e pesquisa em administração: uma postura antropológica. Revista de Administração de Empresas, v. 35, n. 3, p. 64-79, 1995. http://dx.doi.org/10.1590/ S0034-75901995000300008

SILVEIRA, G. A.; SBRAGIA, R.; KRUGLIANSKAS, I. Fatores condicionantes do nível de maturidade em gerenciamento de projetos: um estudo empírico em empresas brasileiras. Revista de Administração, v. 48, n. 3, p. 574-591, 2013.

VOSS, C.; TSIKRIKTSIS, N.; FROHLICH, M. Case research in operations management. International Journal of Operations \& Production Management, v. 22, n. 2, p. 195-219, 2002. http://dx.doi. org/10.1108/01443570210414329

YIN, R. Estudo de caso: planejamento e métodos. Tradução de Daniel Grassi. Revisão Cláudio Damacena. 2. ed. Porto Alegre: Bookman, 2008. 
Anexo 1

\begin{tabular}{|c|c|c|c|c|c|c|}
\hline Atividades do Escritório de Projetos & Grupos & $\begin{array}{l}\text { Está- } \\
\text { gio } 1\end{array}$ & $\begin{array}{l}\text { Está- } \\
\text { gio } 2\end{array}$ & $\begin{array}{l}\text { Está- } \\
\text { gio } 3\end{array}$ & $\begin{array}{l}\text { Está- } \\
\text { gio } 4\end{array}$ & $\begin{array}{l}\text { Está- } \\
\text { gio } 5\end{array}$ \\
\hline $\begin{array}{l}\text { Serviços técnicos de gestão da qualidade nos } \\
\text { projetos }\end{array}$ & ESPECIAL & 1 & 1 & 1 & & \\
\hline Documentação técnica dos produtos & APRENDIZ & & 1 & 1 & & \\
\hline $\begin{array}{l}\text { Desenvolvimento e manutenção dos } \\
\text { procedimentos de gestão de projetos }\end{array}$ & METODOL & & 1 & 1 & 1 & 1 \\
\hline $\begin{array}{l}\text { Gerenciamento dos requisitos dos produtos em } \\
\text { desenvolvimento }\end{array}$ & CLIENTES & & 1 & 1 & & \\
\hline $\begin{array}{l}\text { Gerenciamento dos registros de lições } \\
\text { aprendidas dos projetos }\end{array}$ & APRENDIZ & & 1 & 1 & 1 & 1 \\
\hline $\begin{array}{l}\text { Desenvolvimento de cronogramas e planos de } \\
\text { projeto }\end{array}$ & ESPECIAL & & 1 & 1 & & \\
\hline $\begin{array}{l}\text { Transferência de documentos da engenharia } \\
\text { para a manufatura }\end{array}$ & ESPECIAL & & 1 & 1 & 1 & 1 \\
\hline $\begin{array}{l}\text { Desenvolvimento de documentação comercial } \\
\text { dos produtos }\end{array}$ & CLIENTES & & 1 & 1 & & \\
\hline Gerenciamento dos riscos dos projetos & ESPECIAL & & 1 & 1 & & \\
\hline $\begin{array}{l}\text { Gerenciamento dos custos dos projetos em } \\
\text { parceria com contabilidade }\end{array}$ & MONITOR & & & 1 & 1 & 1 \\
\hline $\begin{array}{l}\text { Gerenciamento da fabricação de partes e peças } \\
\text { para os projetos }\end{array}$ & ESPECIAL & & & 1 & 1 & 1 \\
\hline Gestão dos fornecedores críticos dos projetos & ESPECIAL & & & 1 & 1 & 1 \\
\hline Gestão do sistema de informações de projetos & METODOL & & & 1 & 1 & 1 \\
\hline $\begin{array}{l}\text { Monitoramento e priorização das compras } \\
\text { demandadas pelos projetos }\end{array}$ & ESPECIAL & & & 1 & 1 & 1 \\
\hline $\begin{array}{l}\text { Desenvolvimento e manutenção de indicadores } \\
\text { de gestão de prazos }\end{array}$ & MONITOR & & & 1 & 1 & 1 \\
\hline $\begin{array}{l}\text { Confecção de estruturas de produto no sistema } \\
\text { de informações da empresa }\end{array}$ & ESPECIAL & & & 1 & 1 & 1 \\
\hline $\begin{array}{l}\text { Centralização dos serviços de manutenção } \\
\text { demandados pelo P\&D }\end{array}$ & ESPECIAL & & & 1 & 1 & \\
\hline $\begin{array}{l}\text { Gestão da configuração dos produtos } \\
\text { desenvolvidos }\end{array}$ & ESPECIAL & & & 1 & 1 & 1 \\
\hline Consolidação de cronogramas multiprojetos & MULTIPROJ & & & & 1 & 1 \\
\hline $\begin{array}{l}\text { Execução/aprovação dos orçamentos } \\
\text { multiprojetos (portfólio de projetos) }\end{array}$ & MULTIPROJ & & & & 1 & 1 \\
\hline $\begin{array}{l}\text { Participação em comitês de gestão } \\
\text { interdepartamental }\end{array}$ & MULTIPROJ & & & & 1 & 1 \\
\hline $\begin{array}{l}\text { Treinamento das equipes e gerentes de projetos } \\
\text { em práticas de GP }\end{array}$ & METODOL & & & & 1 & \\
\hline $\begin{array}{l}\text { Desenvolvimento e manutenção de indicadores } \\
\text { de gestão de portfólio }\end{array}$ & MONITOR & & & & & 1 \\
\hline $\begin{array}{l}\text { Planejamento de curto prazo (programação da } \\
\text { produção dos protótipos) }\end{array}$ & ESPECIAL & & & & & 1 \\
\hline $\begin{array}{l}\text { Acompanhamento dos marcos contratuais que } \\
\text { representavam faturamentos }\end{array}$ & MONITOR & & & & & 1 \\
\hline $\begin{array}{l}\text { Realização de reuniões mensais de discussão } \\
\text { multiprojeto }\end{array}$ & MULTIPROJ & & & & & 1 \\
\hline $\begin{array}{l}\text { Comunicação do status dos projetos para a alta } \\
\text { direção }\end{array}$ & MONITOR & & & & & 1 \\
\hline $\begin{array}{l}\text { Desenvolvimento e operação de ferramentas de } \\
\text { gestão de custos de MDO }\end{array}$ & MONITOR & & & & & 1 \\
\hline $\begin{array}{l}\text { Desenvolvimento de planejamento de longo } \\
\text { prazo do P\&D }\end{array}$ & ESTRATEG & & & & & 1 \\
\hline
\end{tabular}

